\title{
Polibotánica
}

ISSN electrónico: 2395-9525

POLIBETÁNICA polibotanica@gmail.com Instituto Politécnico Nacional México

http:www.polibotanica.mx

\section{EVALUACIÓN in vitro DE LA ACTIVIDAD CITOTÓXICA Y ANTITUMORAL DE PLANTAS MEDICINALES RECOMENDADAS EN CUETZALAN DEL PROGRESO, PUEBLA, MÉXICO}

\section{In vitro EVALUATION OF CYTOTOXIC AND ANTITUMOR ACTIVITY OF MEDICINAL PLANTS RECOMMENDED IN CUETZALAN DEL PROGRESO, PUEBLA, MEXICO}

Avelino-Flores, M.C.G.; M.D. Bibbins-Martínez, V. Vallejo-Ruiz, y J. Reyes-Leyva. EVALUACIÓN in vitro DE LA ACTIVIDAD CITOTÓXICA Y ANTITUMORAL DE PLANTAS MEDICINALES RECOMENDADAS EN CUETZALAN DEL PROGRESO, PUEBLA, MÉXICO.

In vitro EVALUATION OF CYTOTOXIC AND ANTITUMOR ACTIVITY OF MEDICINAL PLANTS RECOMMENDED IN CUETZALAN DEL PROGRESO, PUEBLA, MEXICO.

POLIB TÁNICA Instituto Politécnico Nacional
Núm. 47: 113-135 México. Enero 2019 DOI: $10.18387 /$ polibotanica.47.9 


\section{EVALUACIÓN in vitro DE LA ACTIVIDAD CITOTÓXICA Y ANTITUMORAL DE PLANTAS MEDICINALES RECOMENDADAS EN CUETZALAN DEL PROGRESO, PUEBLA, MÉXICO}

\section{In vitro EVALUATION OF CYTOTOXIC AND ANTITUMOR ACTIVITY OF MEDICINAL PLANTS RECOMMENDED IN CUETZALAN DEL PROGRESO, PUEBLA, MEXICO}

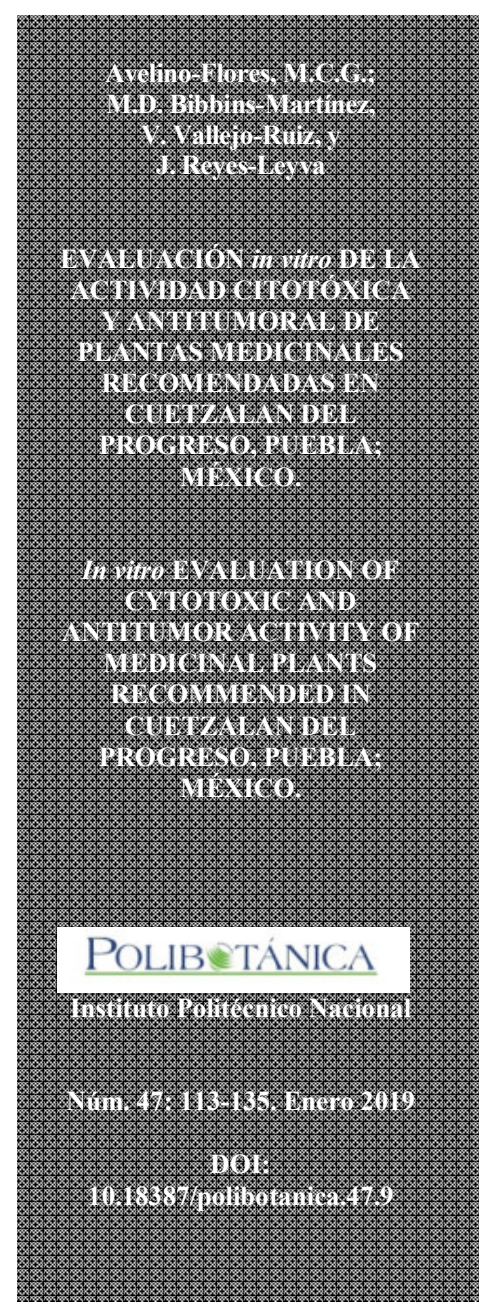

RESUMEN: Las plantas han sido empleadas desde la antigüedad como fuente de medicamentos, algunos principios activos con actividad farmacológica han sido obtenidos exitosamente a partir de éstas, los conocimientos tradicionales sobre su uso han servido para el tratamiento de diversidad de enfermedades. Las plantas Costus pulverulentus, Sechium edule, Tabernaemontana alba y Vernonia patens usadas en la medicina tradicional mexicana de Cuetzalan, Puebla fueron colectadas después de ser seleccionadas de acuerdo a su uso reportado por la comunidad (investigación de campo) y datos reportados en la bibliografía, obteniéndose extractos acuosos e hidroalcohólicos y se evaluó su capacidad para inhibir la proliferación y el crecimiento tumoral in vitro usando la línea celular de cáncer cervical humano SiHa. Dos tipos de ensayos fueron desarrollados: a) Inhibición de la proliferación celular y b) Reducción en el tamaño del tumor in vitro. Los extractos hidroalcohólicos de todas las plantas y el extracto acuoso de T. alba inhibieron la proliferación celular. El extracto hidroalcohólico de las partes aéreas de $S$. edule mostró la mayor actividad inhibitoria a la concentración de $\mathrm{IC}_{50}$ de $16.5 \mu \mathrm{g} / \mathrm{mL}$. Todos los extractos hidroalcohólicos y el extracto acuoso de $T$. alba redujeron el tamaño del tumor formado in vitro. Tanto el extracto hidroalcohólico de $V$. patens como el de $S$. edule tuvieron la mayor actividad sobre los tumores in vitro; $V$. patens redujo su viabilidad en aproximadamente $40 \%$ a partir de la concentración de $1 \mu \mathrm{g} / \mathrm{mL}$, esta misma planta tuvo resultados contrarios para el extracto acuoso que aumentó la proliferación del tumor.

Palabras clave: medicina tradicional, Cuetzalan, actividad citotóxica.

ABSTRACT: Plants have been used since ancient times as a source of medicines, some active ingredients with pharmacological activity have been successfully obtained from these, traditional known about their use have served to treat diversity of diseases. Mexican plants (Costus pulverulentus, Sechium edule, Tabernaemontana alba and Vernonia patens) used in Mexican traditional medicine and recommended by people of 
Cuetzalan del Progreso, Puebla, were collected, aqueous and hydroalcoholic extracts were produced and their capacity to inhibit both the proliferation and tumor growth was evaluated in vitro using the human cervical cancer SiHa cell line. Two types of assays were performed: $a$ ) Inhibition of cell proliferation and $b$ ) Tumor size reduction in vitro. Hydroalcoholic extracts of all the plants and the aqueous extract of $S$. edule and $T$. alba inhibited cell proliferation. $S$. edule hydroalcoholic extract of aerial parts showed the highest inhibitory activity at the smallest concentrations with $\mathrm{IC}_{50}$ of $16.5 \mu \mathrm{g} / \mathrm{mL}$. All hydroalcoholic extracts and the aqueous extract of $T$. alba reduced the size of tumors formed in vitro. The hydroalcoholic extract of $V$. patens showed the highest inhibitory activity $40.5 \%$ at $1 \mu \mathrm{g} / \mathrm{mL}$. Contradictory results were observed with $V$. patens extracts, the aqueous extracts increased tumor size, whereas the hydroalcoholic extract showed the highest inhibitory activity.

Key words: traditional medicine, Cuetzalan, cytotoxic activity.

\section{INTRODUCCIÓN}

El cáncer es una de las principales causas de morbilidad y mortalidad en el mundo, casi una de cada seis defunciones se debe a esta enfermedad. Los cánceres de mama y de cuello uterino se ubican entre los primeros lugares como causa de muerte por tumores en la población del sexo femenino (OMS, 2015). La detección temprana del cáncer de cérvix ha reducido el índice de mortalidad, sin embargo, un importante porcentaje de casos tratados con cirugía, radioterapia y quimioterapia pueden resurgir y llevar incluso a metástasis originando nuevos y más agresivos tumores; la vacuna anti VPH ya es aplicada en algunos países, pero es un tratamiento profiláctico que no cubre la totalidad de serotipos oncogénicos (Bonanni et al., 2015). La investigación en productos naturales ha dado origen a gran parte de los fármacos utilizados en la actualidad, los esfuerzos para descubrir drogas anticancerígenas nuevas se han intensificado en el mundo y aproximadamente el $60 \%$ de principios empleados son de origen natural, especialmente de plantas (Alonso-Castro et al., 2011; Chavan, Damale, Shamkuwar, \& Pawar, 2013; Gordaliza, 2007; Shaikh, Shrivastava, Apte, \& Navale, 2016). En este trabajo se realizó una investigación con los miembros de la Cooperativa Tosepan Titataniske de las plantas medicinales recomendadas por pobladores de la comunidad de Cuetzalan del Progreso, eligiéndose las que podrían presentar actividad contra el cáncer de cérvix evaluándose tanto la actividad citotóxica, como la reducción en el tamaño y proliferación de tumores in vitro de células SiHa de los extractos acuosos e hidroalcohólicos.

\section{MÉtodos}

\section{Investigación y selección del material vegetal}

Se solicitó a las mujeres que forman parte de la cooperativa, un listado con las plantas que ocupan de manera tradicional en el tratamiento de diversos padecimientos, con los datos: nombre común de la planta, su abundancia, forma de reproducción y usos; las plantas fueron seleccionadas de acuerdo a lo reportado en este listado y al uso tradicional, composición química y actividad biológica reportada en la bibliografía, para lo que se consultaron diferentes fuentes sobre la región (Cifuentes \& Ortega, 1990; Flora Medicinal de México II y III, 1994; M. Martínez, 1979). Las partes aéreas de las plantas se recolectaron en la región de Cuetzalan del Progreso Puebla, México con la ayuda de miembros de la cooperativa Tosepan Titataniske y fueron identificadas en el Herbario de la Benemérita Universidad Autónoma de Puebla.

\section{Preparación de extractos}

Las hojas de cada planta se limpiaron y desinfectaron para posteriormente secarse a $40^{\circ} \mathrm{C}$ en horno eléctrico y fueron molidas y extraídas por maceración a temperatura ambiente, protegidas de la luz; para ambos extractos se empleó una proporción planta/disolvente del 10\%; los extractos acuosos se pusieron en agitación continua de $150 \mathrm{rpm}$ en un agitador orbital durante 24 h (Azmir et al., 2013; Betancourt, Saez, Granados, Salazar, \& Ossa, 1999), y los extractos 
hidroalcohólicos (tinturas) se obtuvieron con etanol al 70\% durante siete días (Saldierna, Suárez, García, \& Rodríguez, 2001). Después del tiempo de maceración los extractos se esterilizaron por filtración con una membrana de $0.22 \mathrm{~mm}$ (discos de nylon Gelman Sciencies, Northampton, UK) manteniéndose en condiciones de esterilidad y oscuridad a $-20^{\circ} \mathrm{C}$, fueron llevados a sequedad en rotaevaporador para el cálculo de los rendimientos, estos se reportaron en porcentaje $(\%) \mathrm{m} / \mathrm{m}$ de extracto crudo.

\section{Ensayos de citotoxicidad}

\section{Citotoxicidad de extractos en cultivos adherentes de células SiHa}

La línea celular SiHa (carcinoma cervical con papilomavirus tipo 16) se mantuvo en medio mínimo esencial de Eagle's (MEM) suplementado con 10\% de suero fetal bovino (SFB), 1000 UI de penicilina, $100 \mu \mathrm{g} / \mathrm{mL}$ de estreptomicina e incubadas a $37^{\circ} \mathrm{C}$ en atmósfera húmeda con $95 \%$ de humedad. Una proporción de $1 \times 10^{4}$ células /pozo se depositaron en placas para cultivo celular de 96 pozos con MEM a las condiciones antes mencionadas y se incubaron durante $24 \mathrm{~h}$, después de transcurrido este tiempo el medio se cambió por medio fresco con concentraciones de cada extracto desde 0.1 a $100 \mu \mathrm{g} / \mathrm{mL}$ (concentraciones diferentes fueron empleadas en este rango de concentración) y se incubaron por $72 \mathrm{~h}$ más. La citotoxicidad/ viabilidad celular fue determinada con sales de tetrazolio (MTT) siguiendo la metodología convencional para este método (Wang et al., 2015). Los resultados fueron expresados como porcentaje de viabilidad celular o como índice de citotoxicidad $50\left(\mathrm{IC}_{50}\right)$, que es la concentración que inhibió el 50\% del crecimiento celular; estos valores se estimaron por regresión lineal a partir de las curvas de dosis-respuesta para cada extracto, empleándose el programa KyPlot $v$ 2.0. El quimioterapeútico Bleomicina $(100 \mu \mathrm{g} / \mathrm{mL})$ se usó como control positivo de citotoxicidad y el control negativo fueron células cultivadas bajo las mismas condiciones, pero sin los extractos vegetales ( $\sin$ tratamiento), al control negativo para los experimentos con los extractos hidroalcohólicos se adicionó la cantidad de etanol correspondiente a la máxima concentración experimental empleada.

\section{Actividad sobre los tumores in vitro}

Condiciones de cultivo para el aislamiento y formación de clonas tumorales

El método para el cultivo de las clonas tumorales fue adaptado de Freshney, 1991. El medio de cultivo se preparó con $0.5 \mathrm{~mL}$ de agarosa al $2 \%$ y $0.5 \mathrm{~mL}$ de medio MEM $2 \mathrm{X}$ a temperatura de $45^{\circ} \mathrm{C}$, esta mezcla se vertió en placas para cultivo celular de 24 pozos, 24 h antes de colocar las células. Las monocapas de células $\mathrm{SiHa}$ fueron cosechadas usando tripsina $0.1 \mathrm{M}$ y buffer de fosfatos (PBS), se diluyeron a una concentración de 1 X $10^{5}$ células $/ \mathrm{mL}$ en MEM $2 \mathrm{X}$ por pozo. Un volumen igual de carboximetilcelulosa (CMC) estéril al $2.72 \%$ fue adicionada y mezclada con las células en suspensión y posteriormente la mezcla se colocó en los pozos que contenían previamente el medio agarosa-MEM (suplementado con SFB y antibióticos) preparado, las placas se incubaron a $37^{\circ} \mathrm{C}$ en atmósfera húmeda con $5 \%$ de $\mathrm{CO}_{2}$ y se mantuvieron así hasta observar las clonas tumorales (dos semanas), adicionándose $0.5 \mathrm{~mL}$ de la mezcla agarosa-MEM cada tercer día. Las clonas tumorales se aislaron del medio cuando fueron visibles y posteriormente se depositaron en cajas de cultivo celular para formar monocapas que fueron empleadas para los cultivos de actividad antitumoral (Freshney, 1991).

\section{Inhibición en el crecimiento del tumor in vitro}

La inhibición del crecimiento del tumor in vitro se realizó colocando $1 \times 10^{4}$ UFC tumorales (células SiHa)/500 $\mu \mathrm{L}$ MEM-CMC 2X (1:1); con concentración de los extractos desde 0.1-100 $\mu \mathrm{g} / \mathrm{mL}$ en placas para cultivo celular de 24 pozos con el medio semisólido agarosa-MEM y se incubaron bajo las mismas condiciones de cultivo durante $96 \mathrm{~h}$, transcurrido este tiempo, las colonias tumorales (tumores in vitro) fueron removidas delicadamente por aspiración, y se disgregaron con tripsina; la viabilidad de las mismas se determinó con el ensayo MTT; adicionalmente el tamaño del tumor formado se determinó por micrografía empleando el software Image Tool 3. Todas las pruebas se llevaron a cabo por triplicado en tres experimentos biológicamente independientes. 


\section{Análisis de datos}

Se realizó análisis estadístico de los resultados con un ANOVA de un factor, por comparación múltiple de medias, utilizando el método de Welch con el programa estadístico MiniTab 17.

\section{RESULTADOS}

\section{Selección de plantas y extractos obtenidos}

La tabla 1 muestra el listado de 88 plantas recabado por los miembros de la cooperativa TOSEPAN Titataniske de Cuetzalan, Puebla, que incluye nombre científico y referencias sobre la actividad biológica mencionada de acuerdo a la bibliografía. En ella se destacan cuatro plantas recomendadas para el tratamiento del cáncer: árnica, espinoso, huichin y sábila; de la sábila, el árnica y el huichin existen investigaciones previas sobre esta actividad bajo metodologías semejantes (El-Shemy et al., 2010; Kim, Kacew, \& Lee, 1999; Quintero, Pelcastre, \& Solano, 1999; Via et al., 2015). Con la búsqueda bibliográfica se seleccionaron tres plantas de acuerdo a su empleo tradicional, composición química y actividad farmacológica reportada (Cifuentes \& Ortega, 1990; Flora Medicinal de México II y III, 1994; M. Martínez, 1979), siendo las plantas para el estudio: la caña de venado clasificada como Costus pulverulentus (número de espécimen 12211), originaria de México a Centroamérica y oeste de Sudamérica, asociada a bosque tropical perennifolio; el espinoso clasificado como Sechium edule (número de espécimen 17447), originario de México en climas cálido, semicálido, semiseco y templado; cojón de gato clasificado como Tabernaemontana alba (número de espécimen 31423 ), originaria de México y Centroamérica que se desarrolla en clima cálido; y Ocma, que se clasificó como Vernonia patens (número de espécimen 12 130), originaria de México y norte de Sudamérica, presente en climas cálido, semicálido y templado (Cifuentes \& Ortega, 1990; Flora Medicinal de México II y III, 1994; M. Martínez, 1979). Los especímenes fueron reservados en el Herbario del Jardín botánico de la BUAP.

Tabla 1. Listado de plantas de uso medicinal recomendadas por miembros de la Cooperativa Tosepan Titataniske, Cuetzalan del Progreso, Puebla.

\begin{tabular}{|l|l|l|l|}
\hline \multicolumn{1}{|c|}{ Planta } & \multicolumn{1}{|c|}{$\begin{array}{c}\text { Disponibilidad/ } \\
\text { Forma de } \\
\text { reproducción }\end{array}$} & \multicolumn{1}{c|}{ Uso medicinal } & \multicolumn{1}{c|}{$\begin{array}{c}\text { Nombre científico (referencias sobre } \\
\text { estudios de actividad biológica) }\end{array}$} \\
\hline 1. Ajenjo & abundante / mata & bilis (té) & $\begin{array}{l}\text { Artemisia absinthium L. (W. Ahmad, Hasan, } \\
\text { Abdullah, \& Tarannum, 2010; Govind, 2011) }\end{array}$ \\
\hline 2. Ajo & abundante / semilla & tos, bronquitis & $\begin{array}{l}\text { Allium sativum L. (Sultana, Khan, Safhi, \& A. } \\
\text { Alhazmi H., 2016) }\end{array}$ \\
\hline 3. Ala de murciélago & poco / camote o guía & riñones (té) & $\begin{array}{l}\text { Passiflora coriacea Juss. (UNAM, 2009a). } \\
\text { No existen reportes que corroboren este uso }\end{array}$ \\
\hline 4. Albahacar & abundante / vara & mal aire, cólico menstrual & $\begin{array}{l}\text { Ocimum basilicum (Ghafari et al., 2018; } \\
\text { Rodrigues } \text { et al., 2016) }\end{array}$ \\
\hline 5. Árnica & poco / semilla & $\begin{array}{l}\text { lavar las heridas, desinflamar, } \\
\text { artritis y cicatrizar }\end{array}$ & $\begin{array}{l}\text { Arnica montana / Heterotheca inuloides } \\
\text { (Hostanska, Rostock, Melzer, Baumgartner, \& } \\
\text { Saller, 2012; Rodríguez-Chávez } \text { et al., 2017) }\end{array}$ \\
\hline 6. Asoñate & abundante / vara & mal de aire y limpias & $\begin{array}{l}\text { Brickellia veronicifolia } \text { Kunth (UNAM, 2009b). } \\
\text { No existen reportes que corroboren este uso }\end{array}$ \\
\hline 7. Astzomiate & abundante / vara o & ojeadas & Barkleyanthus salicifolius (Kunth) Rob. et. \\
\hline
\end{tabular}




\begin{tabular}{|c|c|c|c|}
\hline Planta & $\begin{array}{l}\text { Disponibilidad/ } \\
\text { Forma de } \\
\text { reproducción }\end{array}$ & Uso medicinal & $\begin{array}{l}\text { Nombre científico (referencias sobre } \\
\text { estudios de actividad biológica) }\end{array}$ \\
\hline & semilla & & $\begin{array}{l}\text { Brett. (UNAM, 2009q). No existen reportes } \\
\text { que corroboren este uso }\end{array}$ \\
\hline 8. Bayetilla & $\begin{array}{l}\text { abundante / vara o } \\
\text { semilla }\end{array}$ & $\begin{array}{l}\text { lavar heridas, dolor de } \\
\text { estómago (té), cicatrización, } \\
\text { hemorragias, gastritis (agua } \\
\text { de uso con huichin) }\end{array}$ & $\begin{array}{l}\text { Hamelia patens (A. Ahmad, Pandurangan, } \\
\text { Singh, \& Ananad, 2012) }\end{array}$ \\
\hline 9. Verbena & abundante / semilla & bilis & Verbena officinalis L. (Tiwari, 2008) \\
\hline 10. Bugambilia & abundante / vara & tos (té) & $\begin{array}{l}\text { Bougainvillea glabra (Alonso-Castro et al., } \\
\text { 2012; Elumalai, Eswaraiah, Madhavi, \& Ali, } \\
\text { 2012) }\end{array}$ \\
\hline 11. Pelo de elote & abundante / semilla & dolor de riñón & $\begin{array}{l}\text { Estigma maydis (Sukandar, Sigit, \& } \\
\text { Adiwibowo, 2013; Vijitha \& Saranya, 2017) }\end{array}$ \\
\hline 12. Cacaloxochit & poco / tallo & dolor de riñón, colitis & $\begin{array}{l}\text { Plumeria acutifolia (Alhozaimy, Al-Sheddi, \& } \\
\text { Ibrahim, 2017) }\end{array}$ \\
\hline 13. Calahuala & abundante / camote & riñones, mal de orín & $\begin{array}{l}\text { Phlebodium aureum (L.) J. Smith (UNAM, } \\
\text { 2009c). No existen reportes que corroboren } \\
\text { este uso }\end{array}$ \\
\hline 14. Caña de venado & abundante / raíz & riñones y mal de orín & $\begin{array}{l}\text { Costus pulverulentus (UNAM, 2009r). No } \\
\text { existen reportes que corroboren este uso }\end{array}$ \\
\hline 15. Caña morada & NR / semilla & riñones, mal de orín (té) & $\begin{array}{l}\text { Saccharum officinarum L. (UNAM, 2009d). } \\
\text { No existen reportes que corroboren este uso }\end{array}$ \\
\hline 16. Cebolla & abundante / semilla & $\begin{array}{l}\text { hemorragia de menstruación } \\
\text { (hervida con sal), tos, dolor de } \\
\text { oído }\end{array}$ & $\begin{array}{l}\text { Allium cepa (Amir, Dhaheri, Jaberi, Marouqi, } \\
\text { \& Bastaki, 2011; Augusti, 1996) }\end{array}$ \\
\hline 17. Cempasúchil & poco / semilla & bilis & $\begin{array}{l}\text { Tagetes erecta L. (Gopi, Elumalai, \& Jayasri, } \\
\text { 2012) }\end{array}$ \\
\hline 18. Cuetexiquit & $\begin{array}{l}\text { abundante / raíz o } \\
\text { semilla }\end{array}$ & calambres, bilis & No existen reportes para esta planta \\
\hline 19. Chanclán & abundante / rama & recaídas & No existen reportes para esta planta \\
\hline 20. Chilillo & abundante / vara & sarna & $\begin{array}{l}\text { Alchemilla procumbens Rose (UNAM, 2009e). } \\
\text { No existen reportes que corroboren este uso }\end{array}$ \\
\hline 21. Durazno & abundante / semilla & curar heridas y baños & $\begin{array}{l}\text { Prunus persica L. Batsch (Aziz \& Rahman, } \\
\text { 2013; Gasparotto et al., 2014) }\end{array}$ \\
\hline 22. Encino & corteza / semilla & curar heridas y baños & $\begin{array}{l}\text { Género Quercus (Aroonrerk \& Kamkaen, } \\
\text { 2009; Güllüce et al., 2004) }\end{array}$ \\
\hline 23. Epazote & $\begin{array}{l}\text { abundante / semilla } \\
\text { o vara }\end{array}$ & $\begin{array}{l}\text { desparasitante, control de } \\
\text { plagas, sazonar comidas }\end{array}$ & $\begin{array}{l}\text { Chenopodium ambrosioides L. (Kliks, 1985; } \\
\text { Monzote } \text { et al., 2006) }\end{array}$ \\
\hline
\end{tabular}




\begin{tabular}{|c|c|c|c|}
\hline Planta & $\begin{array}{l}\text { Disponibilidad/ } \\
\text { Forma de } \\
\text { reproducción }\end{array}$ & Uso medicinal & $\begin{array}{l}\text { Nombre científico (referencias sobre } \\
\text { estudios de actividad biológica) }\end{array}$ \\
\hline 24. Espinosilla & abundante / vara & fiebre, gripa, tos, recaídas & $\begin{array}{l}\text { Loeselia mexicana (Lam) Brandgee (UNAM, } \\
\text { 2009f). No existen reportes que corroboren } \\
\text { este uso }\end{array}$ \\
\hline 25. Espinoso & abundante / semilla & cáncer & $\begin{array}{l}\text { Sechium edule (Laure, Faca, Izumi, Padovan, } \\
\& \text { Greene, 2006; Monroy-Vázquez et al., } \\
2009 \text { ) }\end{array}$ \\
\hline 26. Estafiate & poco / rama & dolor de estómago, susto & $\begin{array}{l}\text { Artemisia ludoviciana (Zavala-Sánchez, Pérez- } \\
\text { Gutiérrez, Pérez-González, Sánchez-Saldivar, } \\
\text { \& L. Arias-García, 2002) }\end{array}$ \\
\hline 27. Hierbabuena & $\begin{array}{l}\text { abundante / vara o } \\
\text { raíz }\end{array}$ & $\begin{array}{l}\text { desparasitante, dolor de } \\
\text { estómago, cólicos, partos, } \\
\text { sazonar comida, tos, gripa, } \\
\text { diarrea (con canela), lechada }\end{array}$ & $\begin{array}{l}\text { Mentha piperita L. (Saharkhiz et al., 2012; } \\
\text { Vidal et al., 2007) }\end{array}$ \\
\hline 28. Hierba del cáncer & abundante / rama & heridas & $\begin{array}{l}\text { Cuphea aequipetala Cav (Palacios-Espinosa et } \\
\text { al., 2014; Waizel-Bucay, Martínez-Porcayo, } \\
\text { Villarreal-Ortega, Alonso.Cortés, \& A. Pliego- } \\
\text { Castañeda, 2003) }\end{array}$ \\
\hline 29. Hierba dulce & abundante / vara & hemorragia, cólico menstrual & $\begin{array}{l}\text { Lippia dulcis Trev. (UNAM, 2009g). No } \\
\text { existen reportes que corroboren este uso }\end{array}$ \\
\hline 30. Hoja de aguacate & abundante / semilla & $\begin{array}{l}\text { mal de aire (hojas), inflama- } \\
\text { ción, paperas (huesos molidos) }\end{array}$ & $\begin{array}{l}\text { Persea americana (Idris, Ndukwe, \& Gimba, } \\
\text { 2009; Owolabi, Coker, \& Jaja, 2010) }\end{array}$ \\
\hline 31.Hoja de café & abundante / semilla & calmante de nervios, presión & Coffea arabica L. (Godos et al., 2014) \\
\hline 32. Hoja de guayabo & abundante / semilla & diarrea & $\begin{array}{l}\text { Psidium guajava L. (Kamath, Rahul, Ashok, \& } \\
\text { Lakshmi, 2008) }\end{array}$ \\
\hline 33. Hoja de limón & abundante / semilla & calmante de nervios & $\begin{array}{l}\text { Citrus limon (L.) Burm. F. (Cherng-Wei, Wen- } \\
\text { Sung, Chi-Tang, \& Lee-Yan, 2013) }\end{array}$ \\
\hline 34. Hoja de maracuyá & abundante / semilla & calmar nervios & Passiflora edulis sims (Li et al., 2011) \\
\hline 35. Hoja de naranja & abundante / semilla & $\begin{array}{l}\text { infección y empacho, para } \\
\text { granos }\end{array}$ & $\begin{array}{l}\text { Citrus sinensis (L.) Osbeck (Milind \& Dev, } \\
\text { 2012) }\end{array}$ \\
\hline 36. Hoja santa & abundante / vara & curar heridas y baños & $\begin{array}{l}\text { Piper sanctum (Miq.) Schlechtendal (UNAM, } \\
\text { 2009h). No existen reportes que corroboren } \\
\text { este uso }\end{array}$ \\
\hline 37. Huele de noche & abundante / semilla & susto y balo general & $\begin{array}{l}\text { Cestrum nocturnum L. (Pérez-Saad \& } \\
\text { Buznego, 2008) }\end{array}$ \\
\hline 38. Huichin & abundante / vara & $\begin{array}{l}\text { curar heridas, infecciones (té), } \\
\text { desinflamar, fiebre, riñones }\end{array}$ & Verbesina persicifolia D.C. (Via et al., 2015) \\
\hline 39. Izote & poco / tallo & diabetes, mal de oído & $\begin{array}{l}\text { Yucca elephantipes Regel (Cruz \& Andrade- } \\
\text { Cetto, 2015) }\end{array}$ \\
\hline 40. Jarilla & abundante / rama & bilis & Barkleyanthus salicifolius (Kunth) Rob. \& \\
\hline
\end{tabular}




\begin{tabular}{|c|c|c|c|}
\hline Planta & $\begin{array}{l}\text { Disponibilidad/ } \\
\text { Forma de } \\
\text { reproducción }\end{array}$ & Uso medicinal & $\begin{array}{l}\text { Nombre científico (referencias sobre } \\
\text { estudios de actividad biológica) }\end{array}$ \\
\hline & & & Brett. (M. Domínguez et al., 2005) \\
\hline 41. Jengibre & poco / camote & $\begin{array}{l}\text { descongestionar vías } \\
\text { respiratorias, dolor de reumas }\end{array}$ & $\begin{array}{l}\text { Zingiber officinale Roscoe (Badoni, Kumar, } \\
\text { Combrinck, \& Viljoen, 2015) }\end{array}$ \\
\hline $\begin{array}{l}\text { 42. Kouapajxiuit o } \\
\text { Santa Elena }\end{array}$ & $\begin{array}{l}\text { abundante / raíz o } \\
\text { semilla }\end{array}$ & $\begin{array}{l}\text { desparasitante para lombrices, } \\
\text { piquete de víbora (semilla) }\end{array}$ & $\begin{array}{l}\text { Spigelia palmeri Rose (UNAM, 2009i). No } \\
\text { existen reportes para esta actividad }\end{array}$ \\
\hline 43. Laurel & NR / semilla & congestiones & $\begin{array}{l}\text { Litsea glaucescens Kunth (López-Romero et } \\
\text { al., 2018) }\end{array}$ \\
\hline 44. Lengua de ciervo & poco / guía & riñones, mal de orín & $\begin{array}{l}\text { Tectaria heracleifolia (Willd.) Underw. } \\
\text { (UNAM, 2009j). No existen reportes que } \\
\text { corroboren este uso }\end{array}$ \\
\hline 45. Limón & abundante / semilla & para las heridas & $\begin{array}{l}\text { Citrus limon (L.) Burm. F. (UNAM, 2009k). } \\
\text { No existen reportes que corroboren este uso }\end{array}$ \\
\hline 46. Malva & poco /semilla & desinflamar & $\begin{array}{l}\text { Malva parviflora L. (Bouriche, Meziti, } \\
\text { Senator, \& Arnhold, 2011) }\end{array}$ \\
\hline $\begin{array}{l}\text { 47. Maltantzin } \\
\text { morado, blanco, chino }\end{array}$ & $\begin{array}{l}\text { abundante / vara o } \\
\text { raíz }\end{array}$ & susto, pelotillas & $\begin{array}{l}\text { Scutellaria guatemalensis (A. M. A. Martínez } \\
\text { et al., 2001). No existen reportes que } \\
\text { corroboren este uso }\end{array}$ \\
\hline 48. Manzanilla & abundante / semilla & $\begin{array}{l}\text { dolor de estómago, vista, } \\
\text { desinflamar }\end{array}$ & $\begin{array}{l}\text { Matricaria recutita L. (Gupta, Mittal, Bansal, } \\
\text { Khokra, \& Kaushik, 2010) }\end{array}$ \\
\hline 49. Mejorana & poco / vara & $\begin{array}{l}\text { cólicos, } \\
\text { estómago }\end{array}$ & $\begin{array}{l}\text { Origanum majorana L (Al-Howiriny et al., } \\
\text { 2009) }\end{array}$ \\
\hline 50. Menta & poco / planta completa & diarrea y cólicos & Mentha spicata (Moosavy \& Shavisi, 2013) \\
\hline 51. Mirto & abundante / rama & $\begin{array}{l}\text { dolor de oído y cabeza, bilis, } \\
\text { baño para parturientas }\end{array}$ & $\begin{array}{l}\text { Salvia microphylla Kunth y Salvia coccinea } \\
\text { Juss (UNAM, 20091). No existen reportes que } \\
\text { corroboren este uso }\end{array}$ \\
\hline $\begin{array}{l}\text { 52. Mozote, Mozote } \\
\text { morado }\end{array}$ & abundante / semilla & susto & $\begin{array}{l}\text { Bidens pilosa L. (UNAM, } 2009 \mathrm{~m} \text { ). No existen } \\
\text { reportes que corroboren este uso }\end{array}$ \\
\hline 53. Muicle & $\begin{array}{l}\text { abundante / tallo o } \\
\text { rama }\end{array}$ & alferecía & $\begin{array}{l}\text { Justicia spicigera Schl. (UNAM, 2009n). No } \\
\text { existen reportes que corroboren este uso }\end{array}$ \\
\hline 54. Nopal & NR / nopal & diabetes & $\begin{array}{l}\text { Opuntia ficus-indica (L.) Miller (Osuna- } \\
\text { Martínez, Reyes-Esparza, \& Rodríguez- } \\
\text { Fragoso, 2014) }\end{array}$ \\
\hline 55. Ogma & abundante / semilla & disentería & $\begin{array}{l}\text { Vernonia patens Kunth (Pérez-Amador, } \\
\text { Ocotero, Benitez, \& Jiménz, 2008) }\end{array}$ \\
\hline 56. Omequelite & $\begin{array}{l}\text { abundante / vara, } \\
\text { semilla o raíz }\end{array}$ & $\begin{array}{l}\text { quemaduras, después del } \\
\text { parto, tos, resfriado, baños, } \\
\text { hemorragia nasal, vapores } \\
\text { vaginales }\end{array}$ & $\begin{array}{l}\text { Piper auritum Kunth (F. Domínguez, Lozoya, } \\
\& \text { Simon, 2007) }\end{array}$ \\
\hline 57. Orégano & abundante / vara o & bronquitis, mal de ojo & Origanum vulgare L. (Amber, Adnam, Tariq, \\
\hline
\end{tabular}




\begin{tabular}{|c|c|c|c|}
\hline Planta & $\begin{array}{l}\text { Disponibilidad/ } \\
\text { Forma de } \\
\text { reproducción }\end{array}$ & Uso medicinal & $\begin{array}{l}\text { Nombre científico (referencias sobre } \\
\text { estudios de actividad biológica) }\end{array}$ \\
\hline & semilla & & $\&$ Mussarat, 2017) \\
\hline 58. Pagua & poco / semilla & paperas & $\begin{array}{l}\text { Persea schiedeana (Villavicencio \& Pérez, } \\
\text { 2006) }\end{array}$ \\
\hline 59. Peonia & poca / semilla & alferecía en té con rosa blanca & No se posee suficiente información \\
\hline 60. Pimienta & abundante / semilla & bronquitis & $\begin{array}{l}\text { Piper dioica (Sindhu \& Manorama, 2014). No } \\
\text { existen reportes que corroboren este uso }\end{array}$ \\
\hline 61. Plátano gineo & poco / camote & alforre de los niños & $\begin{array}{l}\text { Musa sapientum L. (Lucas, Dumar, \& } \\
\text { CárdenasV.C.A., 2013). No existen reportes } \\
\text { que corroboren este uso }\end{array}$ \\
\hline 62. Poleo & NR / hoja & dolor de estómago & Mentha pulegium L. (Darvishi et al., 2014) \\
\hline $\begin{array}{l}\text { 63. Raíz de milpa } \\
\text { morada }\end{array}$ & NR / semilla & alferecía & $\begin{array}{l}\text { Zea mays L., variedad morada (Pedreschi \& } \\
\text { Cisneros-Zevallos, 2007). No existen reportes } \\
\text { que corroboren este uso }\end{array}$ \\
\hline 64. Romero & abundante / vara & para saumar & $\begin{array}{l}\text { Rosmarinus officinalis L (Okoh, Sadimenko, \& } \\
\text { Afolayan, 2010). No existen reportes que } \\
\text { corroboren este uso }\end{array}$ \\
\hline 65. Rosa de Castilla & abundante / tallo & $\begin{array}{l}\text { fiebre, purga, dolor de cabeza, } \\
\text { limpiar la vista y derrame de } \\
\text { ojos }\end{array}$ & Rosa gallica L. (Bonjar, 2004) \\
\hline 66. Ruda & abundante / rama & bilis, tos, aire, cólicos & $\begin{array}{l}\text { Ruta graveolens L. (García, Martínez, Ortega, } \\
\text { \& Castro, 2010; Saeidinia et al., 2016) }\end{array}$ \\
\hline 67. Sábila & poca / camote & $\begin{array}{l}\text { desinflamar, erisipela, } \\
\text { cicatrización, principios de } \\
\text { cáncer, diabetes (con nopal), } \\
\text { caída de pelo }\end{array}$ & $\begin{array}{l}\text { Aloe vera L. (Singh, Sharma, Kumar, \& } \\
\text { Dudhe, 2010) }\end{array}$ \\
\hline 68. Secapalo & poca / guía & susto & $\begin{array}{l}\text { Género Struthanthus (Leitão, Moreira, } \\
\text { Almeida, \& Guimarães, 2013). No existen } \\
\text { reportes que corroboren este uso }\end{array}$ \\
\hline 69. Sauco & abundante / rama & ojeada, mal de ojo & $\begin{array}{l}\text { Sambucus mexicana Presl (UNAM, 2009o). } \\
\text { No existen reportes que corroboren este uso }\end{array}$ \\
\hline 70. Suape & abundante / rama & cólicos & No existen reportes para esta planta \\
\hline 71. Tabardillo & abundante / rama & cólicos & $\begin{array}{l}\text { Piqueria trinervia Cav (Esparza, Bye, Meckes, } \\
\text { Torres-López, \& M. Jiménez-Estrada, 2007) }\end{array}$ \\
\hline 72. Tacechinolxihuit & $\begin{array}{l}\text { abundante / semilla } \\
\text { o raíz }\end{array}$ & sarampión, viruela & No existen reportes para esta planta \\
\hline 74. Talamat & abundante / raíz & bronquitis, baños, disentería & $\begin{array}{l}\text { Desmodium incanum DC. (Hao et al., 2015). } \\
\text { No existen reportes que corroboren este uso }\end{array}$ \\
\hline 75. Talocma & abundante / rama & ataques & No existen reportes para esta planta \\
\hline
\end{tabular}




\begin{tabular}{|c|c|c|c|}
\hline Planta & $\begin{array}{l}\text { Disponibilidad/ } \\
\text { Forma de } \\
\text { reproducción }\end{array}$ & Uso medicinal & $\begin{array}{l}\text { Nombre científico (referencias sobre } \\
\text { estudios de actividad biológica) }\end{array}$ \\
\hline 76. Tepocihyac & $\begin{array}{l}\text { abundante / raíz o } \\
\text { semilla }\end{array}$ & disentería & No existen reportes para esta planta \\
\hline 77. Té cedrón & poco / rama & diarrea & $\begin{array}{l}\text { Aloysia triphylla Brett. (Ali, El-Beltagi, \& } \\
\text { Nasr, 2011) }\end{array}$ \\
\hline 78. Tiricia & poco / tallo & susto & No existen reportes para esta planta \\
\hline 79. Tzopelitcxihuil & poco / raíz & dolor de estómago & No existen reportes para esta planta \\
\hline 80. Violeta & abundante / rama & estreñimiento & $\begin{array}{l}\text { Viola odorata L. (Akhbari, Batooli, \& Kashi, } \\
\text { 2011) }\end{array}$ \\
\hline 81. Xalcuahuit & abundante / semilla & infección intestinal & No existen reportes para esta planta \\
\hline 82. Xalxocot tzinaca & abundante / semilla & disentería & No existen reportes para esta planta \\
\hline 83. Xomet & abundante / tallo & mal aire & No existen reportes para esta planta \\
\hline 84. Yoloxóchitl & poco/semilla & dolor de corazón & Talauma mexicana DC. (Waizel-Bucay, 2002) \\
\hline 85. Zacapale & abundante / semilla & susto & $\begin{array}{l}\text { Cuscuta jalapensis Sch. (UNAM, 2009p). No } \\
\text { existen reportes que corroboren este uso }\end{array}$ \\
\hline 86. Zanahoria & NR / semilla & vista & Daucus carota L. (Da Silva, 2014) \\
\hline 87. Zapote blanco & poco / semilla & presión & $\begin{array}{l}\text { Casimiroa edulis Llave y Lex (Awaad et al., } \\
\text { 2011) }\end{array}$ \\
\hline 88. Zapote negro & abundante & sarna & \begin{tabular}{|l} 
Diospyros digyna Jacq \\
Sticher, \& Heinrich, 2001)
\end{tabular} \\
\hline
\end{tabular}

$\mathrm{NR}=$ No reportado

Los rendimientos para los extractos tanto acuosos como hidroalcohólicos después de la evaporación de los solventes se presentan en la tabla 2, como puede verse los rendimientos más altos se obtuvieron con las maceraciones hidroalcohólicas.

Tabla 2. Rendimiento de los extractos vegetales obtenidos por maceración, la determinación se realizó tras la evaporación de los solventes.

\begin{tabular}{|l|c|c|}
\hline \multicolumn{1}{|c|}{ Planta } & $\begin{array}{c}\text { Maceración acuosa } \\
(\mathbf{\%} \mathbf{~ m} / \mathbf{m})\end{array}$ & $\begin{array}{c}\text { Maceración hidroalcohólica } \\
\mathbf{( \% ) ~ m / m ) ~}\end{array}$ \\
\hline C. pulverulentus & 8.70 & 14.36 \\
\hline S. edule & 2.56 & 13.60 \\
\hline T. alba & 9.63 & 10.80 \\
\hline V. patens & 5.25 & 16.30 \\
\hline
\end{tabular}




\section{Actividad citotóxica sobre cultivos adherentes de células $\mathrm{SiHa}$}

\section{Extractos acuosos}

Al exponer los cultivos celulares adherentes a los extractos acuosos se observó que los extractos de $C$. pulverulentus y $V$. patens incrementaron la proliferación celular en $11.11 \%$ y $48.6 \%$, respectivamente; a la concentración de $10 \mu \mathrm{g} / \mathrm{mL}$, en relación a las células sin tratamiento; las células tratadas no muestran cambios morfológicos visibles (fig. 1-B y 1-E) al comparase con las células no tratadas (fig. 1-A). Los extractos de $S$. edule y de T. alba inhibieron levemente la proliferación; $S$. edule aumentó el crecimiento celular a las concentraciones de $1 \mu \mathrm{g} / \mathrm{mL}(23.6 \%)$ y $10 \mu \mathrm{g} / \mathrm{mL}$ (43.4\%), sin embargo, a $100 \mu \mathrm{g} / \mathrm{mL}$ reduce el crecimiento en $11.3 \%$ observándose a esta concentración células dañadas y en menor número (fig. 1-C); T. alba mostró un efecto inhibitorio de $15.8 \%$ a la concentración de $100 \mu \mathrm{g} / \mathrm{mL}$ mostrando en la micrografía una menor densidad celular con células desprendidas (fig. 1-D). La bleomicina presentó un máximo de disminución de la proliferación celular a la concentración de $100 \mu \mathrm{g} / \mathrm{mL}$ de $41.6 \%$, observándose al microscopio daño celular severo con muy disminuido número de células (fig. 1-F). En la tabla 3 se pueden observar los valores de viabilidad celular resultantes.

Tabla 3. Actividad de los extractos acuosos a diferentes concentraciones en la viabilidad de células SiHa. La concentración de $0 \mu \mathrm{g} / \mathrm{mL}$ corresponde a células sin tratamiento (control negativo).

\begin{tabular}{|l|c|c|c|c|c|}
\hline \multirow{2}{*}{ Extracto acuosos } & \multicolumn{5}{|c|}{ Viabilidad celular $(\%) \pm \mathbf{D E}$ a diferentes concentraciones $(\boldsymbol{\mu g} / \mathbf{m L})$} \\
\cline { 2 - 6 } & 0 & 0.1 & 1 & 10 & 100 \\
\hline C. pulverulentus & $100 \pm 5.06$ & $103 \pm 3.3$ & $108.6 \pm 0.6$ & $111.11 \pm 2.2$ & $108.6 \pm 2.0^{\mathrm{a}}$ \\
\hline S. edule & $100 \pm 3.0$ & $103 \pm 16.5$ & $123.6 \pm 3.8$ & $143.4 \pm 11.2$ & $88.7 \pm 5.3^{\mathrm{b}}$ \\
\hline T. alba & $100 \pm 1.64$ & $105 \pm 1.04$ & $98.4 \pm 1.1$ & $94 \pm 3.3$ & $84.2 \pm 3.9^{\mathrm{b}}$ \\
\hline V. patens & $100 \pm 10.3$ & $125 \pm 6.8$ & $143.6 \pm 8.9$ & $148.6 \pm 7.9$ & $115.7 \pm 5.7^{\mathrm{a}}$ \\
\hline
\end{tabular}

$\mathrm{DE}=$ desviación estándar $\quad \mathrm{a}, \mathrm{b}=$ Letras diferentes indican diferencia significativa con $p<0.05$.

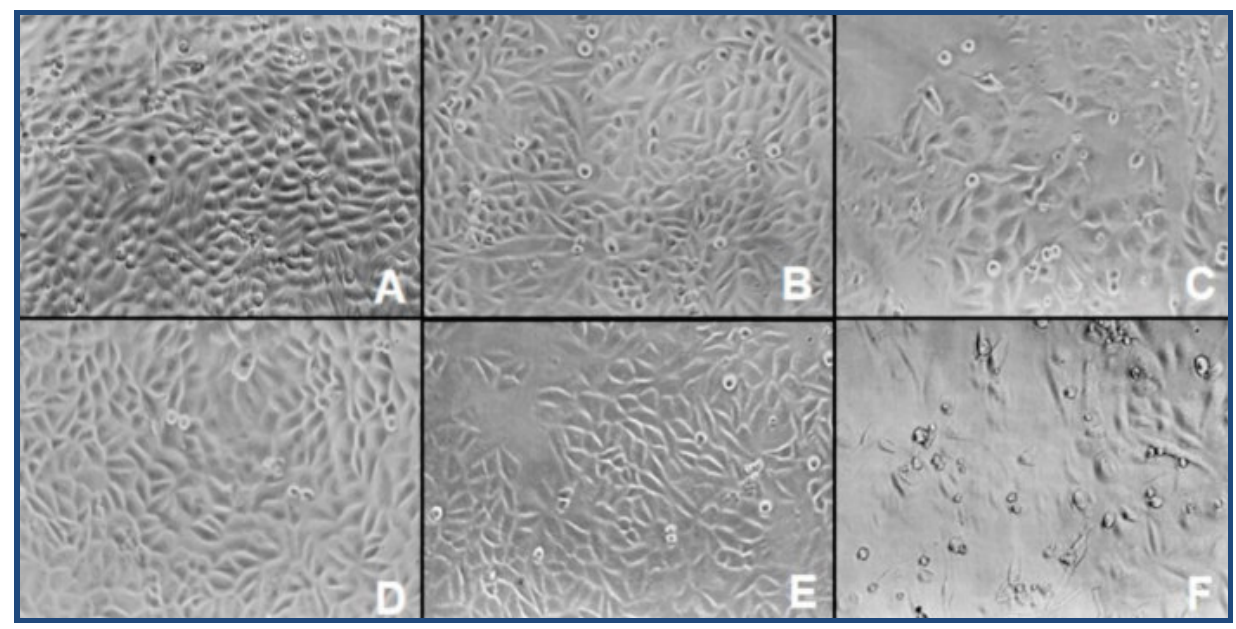

Fig. 1. Micrografías por contraste de fase para las células SiHa tratadas con los extractos acuosos (concentración de $100 \mu \mathrm{g} / \mathbf{m L}$ ): células no tratadas (A), C. pulverulentus (B), S. edule (C), T. alba (D), V. patens (E). Se observan cambios morfológicos para S. edule y T. alba con una reducción en el número de células; en las células expuestas a Bleomicina (F) se observa daño celular importante con abundante detrito celular y disminuido número de células; para C. pulverulentus y V. patens no existen cambios aparentes (Magnificación 200X). 


\section{Extractos hidroalcohólicos}

Todos los extractos hidroalcohólicos disminuyeron la viabilidad de las células SiHa de una manera dosis dependiente, resultando en la muerte de la población celular del $50 \%$ o más a la concentración de $100 \mu \mathrm{g} / \mathrm{mL}$ dependiendo de la planta empleada (tabla 4). El efecto citotóxico de los extractos vegetales sobre las células SiHa se observa en la microscopía (fig. 2-B a 2-E), este efecto no fue producido por la adición de etanol al medio de cultivo (fig. 2-A). El índice de citotoxicidad $50 \%\left(\mathrm{IC}_{50}\right)$ determinado para cada extracto fue de $16.5 \mu \mathrm{g} / \mathrm{mL}$ para $S$. edule, 54.8 $\mu \mathrm{g} / \mathrm{mL}$ para $T$. alba $69.1 \mu \mathrm{g} / \mathrm{mL}$ para $V$. patens y $90.2 \mu \mathrm{g} / \mathrm{mL}$ para $C$. pulverulentus. A la concentración de $100 \mu \mathrm{g} / \mathrm{mL} \mathrm{S}$, edule, T. alba y $V$. patens presentan prácticamente el mismo valor de citotoxicidad, C. pulverulentus tuvo la menor actividad (tabla 4).

Tabla 4. Actividad citotóxica de los extractos hidroalcohólicos en células $\mathrm{SiHa}$ a $100 \mu \mathrm{g} / \mathrm{mL}$ y valor de $\mathrm{IC}_{50}$ determinado para cada planta.

\begin{tabular}{|c|c|c|}
\hline Extracto hidroalcohólico & $\begin{array}{l}\text { Viabilidad celular }(\%) \pm \mathrm{DE} \\
\text { a dosis de } 100 \mu \mathrm{g} / \mathrm{mL}\end{array}$ & $\mathrm{IC}_{50}(\mu \mathrm{g} / \mathrm{mL}) \pm \mathrm{DE}$ \\
\hline C. pulverulentus & $47.9 \pm 2.1^{\mathrm{a}}$ & $90.2 \pm 4.64^{*}$ \\
\hline S. edule & $10.1 \pm 5.6^{b}$ & $16.5 \pm 2.5^{* *}$ \\
\hline T. alba & $11.75 \pm 2.1^{b}$ & $54.8 \pm 3.9^{* * * *}$ \\
\hline V. patens & $15.8 \pm 0.8^{\mathrm{b}}$ & $69.1 \pm 6.9^{* * * *}$ \\
\hline
\end{tabular}

$\mathrm{DE}=$ desviación estándar

$\mathrm{a}, \mathrm{b}, \mathrm{c}, \mathrm{d}=$ Letras diferentes indican diferencia significativa con $p<0.05$

${ }^{*},{ }^{* * * *},{ }^{* * * *}=$ Diferente número de asteriscos indican diferencia significativa con $p<0.05$

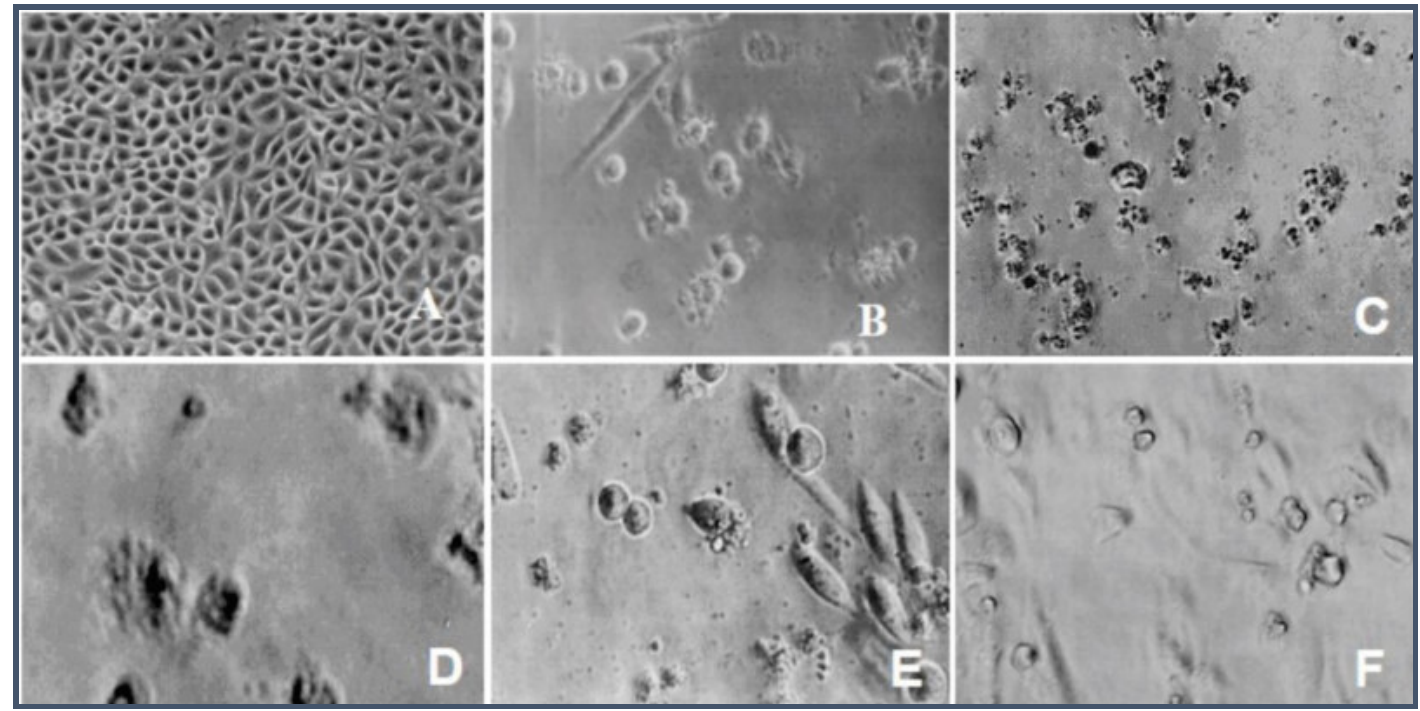

Fig. 2. Micrografías por contraste de fase de células SiHa tratadas con los extractos hidroalcohólicos (100 $\mu \mathbf{g} / \mathbf{m L}$ ): se observan células muertas; algunas con aumento de tamaño y citólisis (D), redondeadas y desprendidas de la monocapa y con abundante detrito celular (B, C, E): Células no tratadas (A), C. pulverulentus (B), S. edule (C),

$T$. alba (D) y $V$. patens (E). El efecto más citotóxico se presenta en las células expuestas a $S$. edule y $T$. alba; la Bleomicina (F) también muestra efecto citotóxico (magnificación 200x). 


\section{Efecto de los extractos en el crecimiento de los tumores in vitro}

\section{Extractos acuosos}

La capacidad de los extractos de las plantas para reducir el tamaño del tumor se ensayó mediante la reproducción de un ensayo clonogénico antiguo que favorece el desarrollo y crecimiento de tumores in vitro (Freshney, 1991). Los extractos acuosos de T. aba y V. patens fueron probados sobre las clonas tumorales de las células $\mathrm{SiHa}$ en el medio de cultivo semisólido. Los extractos acuosos fueron seleccionados por sus efectos contrarios en los cultivos en monocapa (para $T$. alba citotoxicidad y para $V$. patens incremento de la proliferación celular). Los resultados corroboran el efecto de ambos extractos en las células adherentes, como puede observarse en la tabla 5 el extracto acuoso de $T$. alba disminuyó la proliferación (tamaño) de las clonas en los tumores y en el caso de $V$. patens la proliferación del tumor se incrementó. La determinación de viabilidad celular con MTT para los tumores muestra una reducción del $13.6 \%$ para $T$. alba e incremento de $111 \%$ para $V$. patens a $100 \mu \mathrm{g} / \mathrm{mL}$.

Tabla 5. Actividad de extractos acuosos en la proliferación de clonas en los tumores in vitro. La concentración de $0 \mu \mathrm{g} / \mathrm{mL}$ corresponde a células sin tratamiento (control negativo).

\begin{tabular}{|l|c|c|c|c|c|}
\hline \multirow{2}{*}{$\begin{array}{l}\text { Extracto } \\
\text { acuoso }\end{array}$} & \multicolumn{4}{|c|}{ Viabilidad celular $(\%) \pm$ DE a diferentes concentraciones $(\boldsymbol{\mu g} / \mathbf{m L})$} \\
\cline { 2 - 6 } & 0 & 0.1 & 1 & 10 & 100 \\
\hline T. alba & $100 \pm 0.04$ & $106.5 \pm 0.06$ & $126.6 \pm 0.01$ & $90.08 \pm 0.02$ & $86.4 \pm 0.04^{\mathrm{a}}$ \\
\hline V.patens & $100 \pm 0.66$ & $108 \pm 1.5$ & $128 \pm 2.1$ & $137.5 \pm 0.97$ & $211 \pm 2.05^{\mathrm{b}}$ \\
\hline
\end{tabular}

$\mathrm{DE}=$ desviación estándar

$\mathrm{a}, \mathrm{b}=$ Letras diferentes indican diferencia significativa con $p<0.05$.

\section{Extractos hidroalcohólicos}

Todos los extractos hidroalcohólicos redujeron el tamaño y la proliferación del tumor in vitro sin presentar diferencia significativa entre ellos a la concentración de $100 \mu \mathrm{g} / \mathrm{mL}$; sin embargo, el extracto de $V$. patens presentó actividad desde la concentración de $1 \mu \mathrm{g} / \mathrm{mL}(40 \%$ de disminución de la viabilidad) que se mantuvo a las concentraciones de $10 \mu \mathrm{g} / \mathrm{mL}$ y $100 \mu \mathrm{g} / \mathrm{mL}$; S. edule disminuyó en $25.7 \%$ la proliferación del tumor a la concentración de $10 \mu \mathrm{g} / \mathrm{mL}$ y de $39.6 \%$ para la concentración de $100 \mu \mathrm{g} / \mathrm{mL}$; los extractos de $C$. pulverulentus y $T$. alba redujeron en $31.3 \%$ y $32.9 \%$, respectivamente la viabilidad del tumor a la concentración de 100 $\mu \mathrm{g} / \mathrm{mL}$ (tabla 6).

En la figura 3 se observan los tumores in vitro expuestos a dosis de $10 \mu \mathrm{g} / \mathrm{mL}$ de cada extracto, hay una disminución de tamaño en los tratados con $V$. patens con respecto a las demás plantas, los datos obtenidos con el programa Image Tool, fueron: $4044.7 \pm 368.5$ pixeles (tumor sin tratamiento) $7871.33 \pm 368.5$ pixeles (C. pulverulentus), $2073.33 \pm 197.9$ pixeles $(S$. edule), $5816.33 \pm 191.3(T$. alba $)$ y $842.67 \pm 113.52(V$. patens $)$; la tabla 7 presenta los porcentajes determinados para el tamaño de los tumores con respecto al control negativo. 
Tabla 6. Actividad de los extractos hidroalcohólicos a diferentes concentraciones en la viabilidad de clonas en los tumores in vitro. La concentración de $0 \mu \mathrm{g} / \mathrm{mL}$ corresponde a las células no tratadas.

\begin{tabular}{|l|l|l|l|l|l|}
\hline \multirow{2}{*}{$\begin{array}{c}\text { Extracto } \\
\text { hidroalcohólico }\end{array}$} & \multicolumn{5}{|c|}{ Viabilidad celular (\%) \pm DE a diferentes concentraciones $(\mu \mathbf{g} / \mathbf{m L})$} \\
\cline { 2 - 6 } & \multicolumn{1}{c|}{0} & 0.1 & \multicolumn{1}{c|}{1} & \multicolumn{1}{c|}{10} & \multicolumn{1}{c|}{100} \\
\hline C. pulverulentus & $100 \pm 6.25^{*}$ & $124.7 \pm 6.9^{*}$ & $80.5 \pm 6.0^{*}$ & $106.8 \pm 6.7^{* \mathrm{a}}$ & $69.6 \pm 5.7^{* * \mathrm{~d}}$ \\
\hline S. edule & $100 \pm 8.4^{*}$ & $88.2 \pm 2.7^{*}$ & $94.4 \pm 3.4^{*}$ & $74.3 \pm 2.7^{* * \mathrm{~b}}$ & $60.4 \pm 1.3^{* * * \mathrm{~d}}$ \\
\hline T. alba & $100 \pm 7.5^{*}$ & $94.4 \pm 2.5^{*}$ & $106.8 \pm 5.3^{*}$ & $111.4 \pm 6.3^{* \mathrm{a}}$ & $68.1 \pm 2.8^{* * \mathrm{~d}}$ \\
\hline V. patens & $100 \pm 7.7^{*}$ & $88.2 \pm 3.4^{*}$ & $60.4 \pm 3.1^{* *}$ & $63.5 \pm 2.9^{* * \mathrm{c}}$ & $71.2 \pm 3.02^{* * \mathrm{~d}}$ \\
\hline
\end{tabular}

$\mathrm{DE}=$ desviación estándar

$\mathrm{a}, \mathrm{b}, \mathrm{c}, \mathrm{d}=$ Letras diferentes en las columnas indican diferencia significativa con $p<0.05$ entre los extractos a las concentraciones señaladas.

$*, * *, * * *=$ diferente número de asteriscos en una misma fila indican diferencia significativa con $p<0.05$ entre las dosis evaluadas para el mismo extracto.

Tabla 7. Porcentajes de tamaño con respecto al control negativo de los tumores in vitro crecidos en presencia de los extractos hidroalcohólicos a la concentración de $10 \mu \mathrm{g} / \mathrm{mL}$

\begin{tabular}{|l|c|}
\hline \multicolumn{1}{|c|}{ Extracto hidroalcohólico } & $\begin{array}{c}\text { Porcentaje del tamaño de tumor in vitro respecto al } \\
\text { Control negativo }(\%)+\text { DE }\end{array}$ \\
\hline Control negativo & $100+9.11^{\mathrm{a}}$ \\
\hline C. pulverulentus & $194.6+2.4^{\mathrm{bc}}$ \\
\hline S. edule & $51.3+9.6^{\mathrm{d}}$ \\
\hline T. alba & $143.8+11^{\mathrm{ac}}$ \\
\hline V.patens & $20.8+13.5^{\mathrm{d}}$ \\
\hline
\end{tabular}

$\mathrm{DE}=$ desviación estándar

$\mathrm{a}, \mathrm{b}, \mathrm{c}, \mathrm{d}=$ Letras diferentes indican diferencia significativa con $p<0.05$
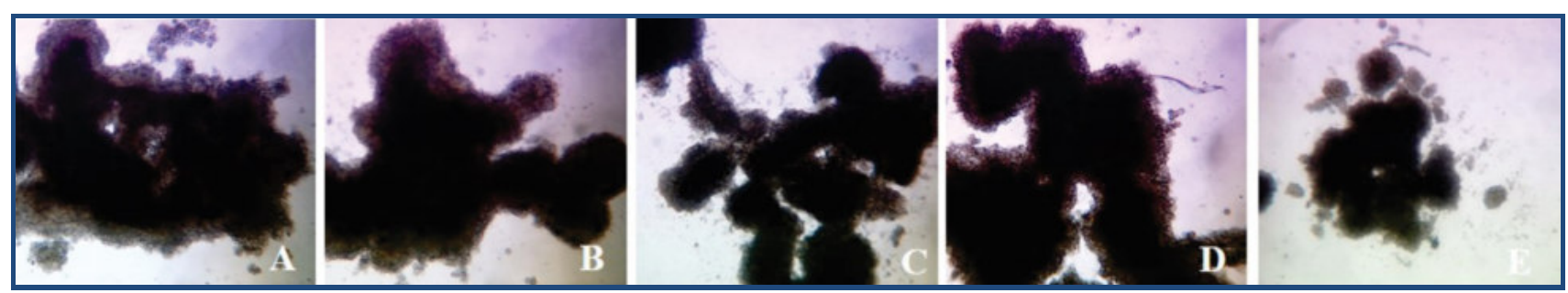

Fig. 3. Reducción del tamaño del tumor in vitro: Los ensayos clonogénicos fueron desarrollados como se mencionó previamente, las células $\mathrm{SiHa}$ se trataron con los extractos hidroalcohólicos por tres días $(10 \mu \mathrm{g} / \mathrm{mL})$. El tamaño del tumor muestra una notable reducción con $V$. patents (E), seguido por $S$. edule (C); para C. pulverulentus

(B) y T. alba (D) no se observa disminución comparando con el control negativo (A). Las micrografías fueron obtenidas con microscopio estereoscópico (Magnificación 20X). 
Comparando los resultados de viabilidad y tamaño de los tumores in vitro, podemos notar que no existe una correspondencia exacta en cuanto a los porcentajes, sin embargo, si existe un patrón de comportamiento, esto sugiere que al determinar la viabilidad tomamos en cuenta a las células vivas, mientras que en el tamaño las células pueden quedar ocultas dentro del tumor y a medida que el tumor se desarrolla el contacto de las células con el extracto disminuye.

\section{DISCUSIÓN}

Tres de los cuatro extractos acuosos probados (C. pulverulentus, $S$. edule y $V$. patens) indujeron un incremento en la proliferación celular a las concentraciones menores de $0.1,1$ y $10 \mu \mathrm{g} / \mathrm{mL}$, este comportamiento ha sido observado también en otros trabajos (Itharat et al., 2004; Whelan \& Ryan, 2003) y puede deberse a un efecto estimulante de compuestos de naturaleza terpenoide como las saponinas los fitoestrógenos y los fitoesteroides que a concentraciones bajas inducen la proliferación celular pero al incrementarse la reducen (Leyva, Navarro-Tovar, LoredoCarrillo, \& Santos, 2011). A la concentración de $100 \mu \mathrm{g} / \mathrm{mL}$ los extractos acuosos de S. edule y $T$. alba presentaron baja actividad citotóxica. Tomando en cuenta los valores de $\mathrm{IC}_{50}$ determinados y comparándolos con la bibliografía, podemos considerar que los extractos hidroalcohólicos de las cuatro plantas poseen potencial para el tratamiento del cáncer, Estrada et al., 2013 considera que valores de $\mathrm{IC}_{50}<100 \mu \mathrm{g} / \mathrm{mL}$ en extractos crudos son candidatos para el aislamiento de metabolitos con acción antitumoral (Estrada, López, Márquez, Martínez, \& Márquez, 2013), mientras que Suffness y Pezzuto en 1990 establecen como parámetro valores de $\mathrm{IC}_{50} \leq 30 \mu \mathrm{g} / \mathrm{mL}$ (Suffness \& Pezzuto, 1990), los extractos hidroalcohólicos de $C$. pulverulentus, $T$. alba y $V$. patens presentaron valores de $\mathrm{IC}_{50}$ menores a $100 \mu \mathrm{g} / \mathrm{mL}$, mientras que el de $S$. edule es menor a $30 \mu \mathrm{g} / \mathrm{mL}$. De las cucurbitáceas, familia botánica a la que pertenece $S$. edule se han aislado proteínas (Dhiman, Gupta, Sharma, Gill, \& Goyal, 2012; Ibrahim, Shalaby, El-Gengaihi, \& Rizk, 1999; Jayaprakasam, Seeram, \& Nair, 2003; Poma, Marcozzi, Cesare, Carmignani, \& Sapano, 1999; Rajasree, Sibi, Francis, \& William, 2016) inhibidoras de proteasas y proteínas tipo RIP (proteínas inhibidoras de ribosomas) en semillas (Laure et al., 2006; Wu, Chow, \& Lin, 1998), ambas poseen potencial anticancerígeno, los frutos del chayote mostraron actividad citotóxica en células L929 y HeLa a concentraciones de $\mathrm{IC}_{50}$ de 2.22 y $2.68 \mathrm{mg} / \mathrm{mL}$ respectivamente, las fracciones del extracto metanólico de los frutos tuvieron en células $\mathrm{L} 929$ valores de $\mathrm{IC}_{50}$ menores $(0.047 \mathrm{mg} / \mathrm{mL})$, el análisis fitoquímico mostró la presencia de ácidos grasos saturados e insaturados (Monroy-Vázquez et al., 2009); los extractos alcohólicos del fruto de diferentes variedades de chayote entre ellas: virens levis, nigum xalapensis y nigrum spinosum presentan metabolitos con actividad antiproliferativa y citotóxica, diferentes híbridos de Sechium edule (Jacq.) Sw. favorecen su efecto a partir de la modificación de su metabolismo secundario (Monroy-Vázquez et al., 2009; Uriostegui, 2014).

Costus pulverulentus (Costaceae) mostró la menor actividad citotóxica con un $\mathrm{IC}_{50}$ de 90.2 $\mu \mathrm{g} / \mathrm{mL}$, en el extracto alcohólico de los tallos se ha identificado campesterol, stigmasterol, $\beta$ sitosterol, ácido vanílico, entre otros con un moderado efecto anticonceptivo y antiinflamatorio; este mismo extracto mostró una baja citotoxicidad en células PC-3 de carcinoma de próstata con una $\mathrm{IC}_{50}$ de $179 \pm 23.2 \mu \mathrm{g} / \mathrm{mL}$ (Alonso-Castro et al., 2016), valores de $\mathrm{IC}_{50}$ mayores que para las células $\mathrm{SiHa}$, en el extracto hexánico crudo se observó potencial antioxidante y antitopoisomerasa (Niño, Correa, Cardona, \& Marino, 2011) que podrían contribuir a la citotoxicidad mostrada en este estudio. El extracto de $V$. patens de la familia Compositae mostró una $\mathrm{IC}_{50}$ de $69.1 \mu \mathrm{g} / \mathrm{m}$, miembros de este mismo género han sido reportados por su actividad citotóxica, $V$. guineensis presenta actividad citotóxica sobre células de linfoma y sarcoma de Kaposi del $100 \%$ a concentraciones $8 \mu \mathrm{g} / \mathrm{mL}$, induce apoptosis y reduce el tamaño de tumores $(40 \%)$ inducidos en ratones nude (Toyang, Toyang, \& Toyeng, 2012), podemos destacar que en los tumores in vitro desarrollados en nuestra investigación $V$. patens fue la que produjo el efecto inhibitorio mayor a menor concentración; $V$. amygdalina ha sido ampliamente estudiada por su actividad en células de cáncer de mama (MCF-7, MDA-MB-231) el extracto 
etanólico presentó concentraciones de $\mathrm{IC}_{50}$ de $56 \mu \mathrm{g} / \mathrm{mL}$ y $46 \mu \mathrm{g} / \mathrm{mL}$, respectivamente, sugiriéndose un arresto del ciclo celular (Wong, Woo, Hsu, \& Tan, 2013), en otro estudio el extracto acuoso presentó $\mathrm{IC}_{50}$ de $5.67 \pm 2 \mu \mathrm{g} / \mathrm{mL}$ para las células MCF-7 (Howard, Johnson, Pervin, \& Izevbigie, 2015), los resultados para estas muestran mayor actividad que los obtenidos para las células $\mathrm{SiHa}$, lo que puede deberse al tipo celular y a la especie. El extracto hidroalcohólico de T. alba (Apocynaceae) tuvo una concentración de $\mathrm{IC}_{50}$ de $54.8 \mu \mathrm{g} / \mathrm{mL}$, los efectos citotóxicos de algunos miembros de esta familia han sido probados con diferentes líneas celulares de cáncer humano (Itharat et al., 2004; Kuo et al., 1999) y una importante actividad antioxidante ha sido reportada para este género (Moussa, Emam, Diab, Mahmoud, \& Mahmoud, 2011); T. catharinensis produjo citólisis con extractos obtenidos con fluídos supercríticos a la concentración de $25 \mu \mathrm{g} / \mathrm{mL}$ con disminución de la proliferación de células tumorales (mama, pulmón, melanoma, colon, próstata y riñón) del 50\% (Pereira, Carvalho, \& Meireles, 2006), monoterpenos indol alcaloides aislados de T. elegans indujeron apoptosis aproximadamente del $40 \%$ a las 24 h de incubación en células de HuH-7 de hepatoma humano (Mansoor, Ramalho, Mulhovo, Rodrigues, \& Ferreir, 2009). No existen reportes asociados a la actividad citotóxica de $T$. alba, y $V$. patens por lo que este estudio sería el primer reporte acerca de su actividad citotóxica con un valor de $\mathrm{IC}_{50}$ dentro de los valores establecidos por el NCI.

\section{CONCLUSIONES}

Los extractos hidroalcohólicos de las plantas seleccionadas de acuerdo a su uso tradicional, a la composición química y a la actividad biológica: C. pulverulentus, S. edule, T. alba y V. patens, poseen potencial antitumoral por lo que se recomienda la caracterización química para determinar el principio activo y la evaluación de la capacidad antitumoral in vivo.

\section{AGRADECIMIENTOS}

Nuestros más sinceros agradecimientos a las instituciones involucradas en la realización de este proyecto: Centro de Investigación en Biotecnología Aplicada, Instituto Politécnico Nacional; Laboratorio de Biología Molecular y Virología, Centro de Investigación Biomédica de Oriente, Instituto Mexicano del Seguro Social y a la Benemérita Universidad Autónoma de Puebla (Facultad de Ingeniería Química y Herbario); a todos los miembros de la Cooperativa Tosepan Titataniske, y especialmente al Señor Epifanio Martínez por su apoyo para la realización de la encuesta y recolección y de los materiales vegetales.

\section{LITERATURA CITADA}

Ahmad, A., Pandurangan, A., Singh, N., \& Ananad, P. . (2012). A mini review on chemistry and biology of Hamelia patens (Rubiaceae). Pharm J, 4(29), 1-4.

Ahmad, W., Hasan, A., Abdullah, A., \& Tarannum, T. (2010). Medicinal importance of Artemisia absinthium Linn (Afsanteen) in Unani Medicine: A Review. Hipp. J. Unani Med., 5(4), 117-125.

Akhbari, M., Batooli, H., \& Kashi, F. J. (2011). Composition of essential oil and biological activity of extracts of Viola odorata L. from central Iran. Nat Prod Res, 26(9), 802809.

Al-Howiriny, T., Alsheikh, A., Alqasoumi, S., Al-Yahya, M., ElTahir, K., \& Rafatullah, S. (2009). Protective effect of Origanum majorana L. "Marjoram" on various models of gastric mucosal injury in rats. Am J Chin Med, 37(3), 531-545.

Alhozaimy, G. A., Al-Sheddi, E. S., \& Ibrahim, T. A. (2017). Biological activity and isolation of compounds from bark of Plumeria acutifolia. Pharmacogn Mag, 13(3), S505-S511. 
Ali, H. F. M., El-Beltagi, H. S., \& Nasr, N. F. (2011). Evaluation of antioxidant and antimicrobial activity of Aloysia triphylla. Electronic J Enviromental, Agric. Food Chem., 10(8), 2689-2699.

Alonso-Castro, A. J., Maldonado-Miranda, J. J., Martínez, A. Z.-, Jacobo-Salcedo, M. R., Fernández-Galicia, C., Figueroa-Zuñiga, L. A., ... Carranza-Álvarez, C. (2012). Medicinal plants used in the Huasteca Potosina, México. J. Ethnopharm., 143, 292 298.

Alonso-Castro, A. J., Villareal, M. ., Salazar-Olivo, L. A., Gómez-Sánchez, M., Domínguez, F., \& García-Carrancá, A. (2011). Mexican medicinal plants used for cancer treatment: Pharmacological, phytochemical and ethnobotanical studies. J. Ethnopharm., 133, 945-972.

Alonso-Castro, A. J., Zapata-Morales, J. M., Gonzáles-Chavez, M. M., Carranza-Álvarez, C., Hernández-Benavides, D. M., \& Hernández Morales, A. (2016). Pharmacological effects and toxicity of Costus pulverulentus C. J. Ethnorpharmacol., 180, 124-130.

Amber, R., Adnam, M., Tariq, A., \& Mussarat, S. (2017). A review on antiviral activity of the Himalayan medicinal plants traditionally used to treat bronchitis and related symptoms. J. Pharm. Pharmacol., 69, 109-122.

Amir, N., Dhaheri, A. Al, Jaberi, N. Al, Marouqi, F. Al, \& Bastaki, S. M. A. (2011). Comparative effect of garlic (Allium sativum), onion (Allim cepa) and black seed (Nigella sativa) on gastric acid secretion and gastric ulcer. Res. Rep. Med. Chem., 1, 3-9.

Aroonrerk, N., \& Kamkaen, N. (2009). Anti-inflammatory activity of Quercus infectoria, Glycyrrhiza uralensis, Kaempferia galanga and Coptis chinensis the main components of Thai herbal remedies for apfthous ulcer. J. Health Res., 23(1), 17-22.

Augusti, K. T. (1996). Therapeutic values of onion (Allium cepa) abd garlic (Allium sativum L.). Indian J. Exp. Biol., 34(7), 634-640.

Awaad, A. C., Al-Jaber, N. A., Soliman, G. A., Al-Outhman, M. R., Zain, M. E., Moses, J. E., \& El-Meligy, R. M. (2011). Biological Activities of Casimiroa edulis Leaf Extracts and isolated compounds. Phytother. Res., 26(3), 452-457.

Aziz, C., \& Rahman, H. (2013). Biological activity of Prunus persica L. batch. Med. Plants Res., 7(15), 947-951.

Azmir, J., Zaidul, I. S. M., Rahaman, M. M., Sharif, K. M., Mohamed, A., Sahena, F., ... Omar, A. K. M. (2013). Techniques for extraction of bioactive compounds from plants materials: A review. Food Enginer, 117, 426-436.

Badoni, S. R., Kumar, C. D., Combrinck, S., \& Viljoen, M. (2015). Gingerols and Shogaols: Important nutraceutical principles from Ginger. Phytochem, 117, 554-568.

Betancourt, L. A. G., Saez, J., Granados, H., Salazar, A., \& Ossa, J. E. (1999). Antitumor and antiviral activity of colombian medicinal plants extracts. Mem. Inst. Oswaldo Cruz, 94, 531-534.

Bonanni, P., Bechini, A., Donato, R., Capei, R., Sacco, C., Levi, M., \& Boccalini, S. (2015). Human papiloma virus vaccination: impact and recommendations across the world. Ther. Adv. Vaccines, 3(1), 3.12.

Bonjar, S. (2004). Evaluation of antibacterial properties of some medicinal plants used in Iran. J. Ethnopharmacol., 94, 301-305.

Bouriche, H., Meziti, H., Senator, A., \& Arnhold, J. (2011). Anti-inflammatory, free radicalscavenging, and metal-chelating activities of Malva parviflora. Pharm. Biol., 49(9), 942-946.

Chavan, S., Damale, M. G., Shamkuwar, P. B., \& Pawar, D. P. (2013). Traditional Medicinal Plants for Anticancer Activity. Int. J. Curr. Pharm. Res., 5(4), 50-54.

Cherng-Wei, H., Wen-Sung, L., Chi-Tang, H., \& Lee-Yan, S. (2013). Antidepressant-like effect of lemon essential oil is through a modulation in the levels of norepinephrine, dopamine, and serotonin in mice: Use of the tail suspension test. J. Functional Foods, $5(1), 370-379$.

Cifuentes, E., \& Ortega, M. A. (1990). Herbolaria y Tradiciones etnomédicas en un pueblo nahua. (U. N. A. de México, Ed.) (Primera). México: Universidad Nacional Autónoma de México. 
Cruz, E. C., \& Andrade-Cetto, A. (2015). Ethnopharmacological field study of the plants used to treat type 2 diabetes among the Cakchiquels in Guatemala. Journal of Ethnopharmacology, 159(2015), 238-244. https://doi.org/doi.org/10.1016/j.jep. 2014.11.021

Da Silva, D. J. C. (2014). Nutritional and Health benefits of carrots and their seed extracts. Food Nut. Sci., 5, 2147-2156.

Darvishi, E., Kazemi, E., Kahrizi, D., Bahraminejad, S., Mansouri, M., Chaghakaboudi, S. R., \& Khani, Y. (2014). Optimization of Callus induction in Pennyroyal (Mentha pulegium). J. Appl. Biotech. Rep., 1(3), 97-100.

Dhiman, K., Gupta, A., Sharma, D. K., Gill, N. S., \& Goyal, A. (2012). A Review on the medicinally important plants of the Cucurbitaceae. As. J. Clin. Nutr., 4(1), 16-26.

Domínguez, F., Lozoya, X., \& Simon, J. (2007). Tissue culture regeneration of a Medicinal plant from Mexico: Piper auritum Kunth. Hort. Sci., 41(1), 207-209.

Domínguez, M., Nieto, A., Marín, J. C., Keck, A. S., Jeffery, E., \& Céspedes, C. L. (2005). Antioxidant Activities of Extracts from Barkleyanthus salicifolius (Asteraceae) and Penstemon gentianoides (Scrophulariaceae). J. Agric. Food Chem., 53, 5889-5895.

El-Shemy, H. A., Aboul-Soud, M. A. M., Nassr-Allah, A. A., Aboul-Enein, K. M., Kabash, A., \& Yagis, A. (2010). Antitumor Properties and modulation of antioxidant Enzymes Activity by Aloe vera leaf active principles isolated via Supercritical carbon dioxide extraction. Curr. Med. Chem., 17, 129-138.

Elumalai, L., Eswaraiah, M. C., Madhavi, L. K., \& Ali, H. S. (2012). In-vivo screening of Bougainvillea glabra leaves for its Analgesic, Antipyretic and Anti-inflammatory activities. Asian J. Pharm. Sci., 2(3), 85-87.

Esparza, R. R. de, Bye, R., Meckes, M., Torres-López, J., \& M. Jiménez-Estrada. (2007). Antibacterial Activity of Piqueria trinervia, a Mexican Medicinal Plant Used to Treat Diarrhea. Pharm. Biol, 45(6), 446-452.

Estrada, N., López, J., Márquez, D., Martínez, A., \& Márquez, M. (2013). Evaluación citotóxica de fracciones de esponjas marinas del Caribe Colombiano. Rev. Fac. de Cienc. Universidad Nacional de Colombia, Sede Medellín, 2(1), 35-51.

Flora Medicinal de México II y III. (1994). Instituto Nacional Indigenista.

Freshney, R. I. (1991). Cultivos en suspensión. In Culture of animal cells a manual of basic technique (segunda, pp. 238-240). Nueva Jersey, Estados Unidos: Wiley-Liss.

García, L. C., Martínez, R. A., Ortega, S. J. ., \& Castro, B. F. (2010). Componentes químicos y su relación con las actividades biológicas de algunos extractos vegetales. Rev. Química Viva, 2(9), 86-96.

Gasparotto, J., Somensi, N., Bortolin, R. C., Girardi, C. S., Klafke, K., Rabelo, T. K., ... Pens, G. D. (2014). Effects of different products of peach (Prunus persica $\mathrm{L}$. Batsch) from a variety developed in southern Brazil on oxidative stress and inflammatory parameters in vitro and ex vivo. J. Clin. Biochem. Nutr., 55(2), 110-119.

Ghafari, S., Tavakoli, Z., Shirooyeh, P., Meybodi, R. N., Behmanesh, E., Mokaberinejad, R., ... Fahimi, S. (2018). The herbal medicine proposed by Iranian Traditional Medicine (Persian Medicine) for treatment of primary Dysmenorrhea: A Review. Trad. Integr. Med., 3(1), 30-42.

Godos, J., Pluchinotta, F. R., Marventano, S., Buscemi, S., Volti, G. L., \& Galvano, F. (2014). Coffe components and cardiovascular risk: benefical and detrimental effects. Internal. J. Food Sci. Nut., 65(8), 935-936.

Gopi, G., Elumalai, A., \& Jayasri, P. (2012). A Concise Review On Tagetes erecta. Inter. J. Phytopharm. Res., 3(3), 16-19.

Gordaliza, M. (2007). Natural products as leads to anticancer drugs. Clin. Transl. Oncol., 9, 767-776.

Govind, P. (2011). Medicinal plants against liver diseases. Inter. Res. J. Pharm., 2(5), 115-121.

Güllüce, M., Adigüzel, A., Ögütcü, H., Sengül, M., Karaman, I., \& Sahin, F. (2004). Antimicrobial effects of Quercus ilex L. extract. Phytother. Res., 18(3), 208-211.

Gupta, V., Mittal, P., Bansal, P., Khokra, S., \& Kaushik, D. (2010). Pharmacological Potential of Matricaria recutita- A review. Internal. J. Pharm. Sci. \& Drug Res., 2(1), 12-16. 
Hao, B., Caulfield, J. C., Hamilton, M. L., Pickett, J. A., Midega, C. A. O., Khan, Z. R., ... Hooper, A. M. (2015). The biosynthesis of allelopathic di-C-glycosylflavones from the roots of Desmodium incanum (G. Mey.) DC. Org. Biomol. Chem., 13, 11663-11673.

Hostanska, K., Rostock, M., Melzer, J., Baumgartner, S. S., \& Saller, R. (2012). A homeopathic remedy from arnica, marigold, St. John's wort and comfrey accelerates in vitro wound scratch closure of NIH $3 \mathrm{~T} 3$ fibroblasts. BMC Complementary and Alternative Medicine, 12, 100. https://doi.org/10.1186/1472-6882-12-100

Howard, C. B., Johnson, W. K., Pervin, S., \& Izevbigie, E. B. (2015). Recent perspectives on the anticancer properties of aqueous extracts of Nigerian Vernonia amigdalina. Botanics, 5, 65-76.

Ibrahim, N., Shalaby, A. S., El-Gengaihi, S., \& Rizk, M. (1999). Antitumor activity of proteins and polysaccharides of certain cucurbitaceous plants. ISHS Acta Horticulturae 501: II WOCMAP Congress Medicinal and Aromatic Plants, Part 2: Pharmacognosy, Pharmacology, Phytomedicine, Toxicology, 234-237.

Idris, S., Ndukwe, G. I., \& Gimba, C. E. (2009). Preliminary Phytochemical screening and antimicrobial activity of seed extracts of Persea americana (Avocado pear). Bajopas, 2(1), 173-176.

Itharat, A., Houghton, P. J., Eno-Amooquaye, E., Burke, P. J., Sampson, J. H., \& Raman, A. (2004). In vitro cytotoxic activity of Thai medicinal plants used traditionally to treat cancer. J. Ethnopharm, 90, 33-38.

Jayaprakasam, B., Seeram, N. P., \& Nair, M. G. (2003). Anticancer and antiinflammatory activities of cucurbitacins from Cucurbita andreana. Cancer Lett, 189, 11-16.

Kamath, J. V., Rahul, N., Ashok, K. C. K., \& Lakshmi, S. M. (2008). Psidium guajava L: A review. International J. Green Pharm., 2(1), 9-12.

Kim, H. S., Kacew, S., \& Lee, B. M. (1999). In vitro chemopreventive effects of plant polysaccharides (Aloe barbadensis Miller, Lentinus edodes, Ganoderma lucidum and Coriolus versicolor). Carcinogenesis, 20(8), 1637-1640.

Kliks, M. M. (1985). Studies on the traditional herbal anthelmintic Chenopodium ambrosioides L.: Ethnopharmacological evaluation and clinical field trials. Soc. Sci. Med., 21(8), 879-886.

Kuo, Y. h., Sun, C. M., Tsai, W. J., Ou, J. h., Chen, W. P., \& Lin, C. Y. (1999). Blocking of cell proliferation, cytokines production and genes expression following administration of chinese herbs in the human mesangial cells. Life Sci., 64, $2089-2099$.

Laure, H. J., Faca, V. M., Izumi, C., Padovan, J. C., \& Greene, L. J. (2006). Low molecular weight squash trypsin inhibitors from Sechium edule seeds. Phytochem., 67, 362-370.

Leitão, F., Moreira, D. de L., Almeida, M. Z. de, \& Guimarães, L. S. (2013). Secondary metabolites from the mistletoes Struthanthus marginatus and Struthanthus concinnus (Loranthaceae). Biochem. Systematics Ecol., 48, 215-218.

Leonti, M., Vibrans, H., Sticher, O., \& Heinrich, M. (2001). Ethnopharmacology of the Popoluca, Mexico: an evaluation. J. Pharm. Pharmacol., 53, 1653-1669.

Leyva, E., Navarro-Tovar, G., Loredo-Carrillo, S. E., \& Santos, D. M. S. (2011). Biosíntesis y actividad biológica de fitoestrógenos y fitoesteroides. Bol. Soc. Quím. Méx, 5(2,3), 35-43.

Li, H., Zhou, P., Yang, Q., Shen, Y., Deng, J., Li, L., \& Zhao, D. (2011). Comparative studies on anxiolytic activities and flavonoid compositions of Passiflora edulis 'edulis' and Passiflora edulis 'flavicarpa'. Journal of Ethnopharmacology, 133(3), 1085-1090. https://doi.org/10.1016/j.jep.2010.11.039

López-Romero, J. C., González-Ríos, H., Peña-Ramos, A., Velazquez, C., Navarro, M., RoblesZepeda, R., ... Hernández, J. (2018). Seasonal Effect on the Biological Activities of Litsea glaucescens Kunth Extracts. Evidence-Based Complementary and Alternative Medicine, 2018, 1-11. https://doi.org/10.1155/2018/2738489

Lucas, A. J. C., Dumar, Q. V., \& CárdenasV.C.A. (2013). Caracterización de harina y almidón obtenidos a partir de plátano guineo AAAea (Musa sapientum L.). Acta Agronómica, 62(2), 83-96.

Mansoor, T. A., Ramalho, R. M., Mulhovo, S., Rodrigues, C. M. P., \& Ferreir, M. J. U. (2009). Induction of apoptosis in HuH-7 cancer cells by monoterpene and b-carboline índole 
alkaloids isolated from the leaves of Tabernaemontana elegans. Bioorg. Med. Chem. Lett., 19, 4255-4258.

Martínez, A. M. A., Evangelista, O. V., Mendoza, C. I., Morales, G. G., Toledo, O. G., \& Wong, L. A. (2001). Catálogo de plantas útiles de la Sierra Norte de Puebla, México (Segunda). UNAM.

Martínez, M. (1979). Catálogo de nombres vulgares y científicos de Plantas Mexicanas. Fondo de Cultura Económica.

Milind, P., \& Dev, C. (2012). Orange: Range of benefits. International Res. J. Pharm., 3(7), $59-63$.

Monroy-Vázquez, M. E., Soto-Hernández, M., Cadena-Iñiguez, J., Santiago-Osorio, E., RuizPosadas, L. M., \& Rosas-Acevedo, H. (2009). Estudio biodirigido de un extracto alcohólico de frutos de Sechium edule (Jacq.) Swartz. Agrociencia, 43(8), 777-790.

Monzote, L., Montalvo, A. M., Almanonni, S., Scull, R., Miranda, M., \& Abreu, J. (2006). Activity of the essential oil from Chenopodium ambrosioides grown in Cuba against Leishmania amazonensis. Chemotherapy, 52(3), 130-136.

Moosavy, M. H., \& Shavisi, N. (2013). Determination of Antimicrobial Effects of Nisin and Mentha spicata Essential Oil against Escherichia coli O157:H7 Under Various Conditions (pH, Temperature and $\mathrm{NaCl}$ Concentration). Pharm. Sci., 19(2), 61-67.

Moussa, A. M., Emam, A. M., Diab, Y. M., Mahmoud, M. E., \& Mahmoud, A. S. (2011). Evaluation of antioxidant potential of 124 Egyptian plants with emphasis on the action of Punica granatum leaf extract on rats. Int. Food Res. J., 18, 535-542.

Niño, J., Correa, Y. M., Cardona, G. D., \& Marino, M. O. (2011). Antioxidant and antitopoisomerase activities in plant extracts of some Colombian flora from La Marcada Natural Regional Park. Rev. Biol. Trop, 59(3), 1089-1097.

Okoh, O. O., Sadimenko, A. P., \& Afolayan, A. J. (2010). Comparative evaluation of the antibacterial activities of the essential oils of Rosmarinus officinalis L. obtained by hydrodistillation and solvent free microwave extraction methods. Food Chem, 120(1), 308-312.

OMS. (2015). Cáncer: Datos y cifras. Retrieved April 1, 2018, from http://www.who.int/ mediacentre/factsheets/fs297/es/

Osuna-Martínez, U., Reyes-Esparza, J., \& Rodríguez-Fragoso, L. (2014). Cactus (Opuntia ficus-indica): A Review on its Antioxidants Properties and Potential Pharmacological Use in Chronic Diseases. Natural Products Chemistry \& Research, 2(6), 153. https://doi.org/10.4172/2329-6836.1000153

Owolabi, M. A., Coker, H. A. B., \& Jaja, S. I. (2010). Bioactivity of the phytoconstituents of the leaves of Persea americana. J. Med. Plants Res., 4(12), 1130-1135.

Palacios-Espinosa, J. F., Arroyo-García, O., García-Valencia, G., Linares, E., Bye, R., \& I. Romero. (2014). Evidence of the anti-Helicobacter pylori, gastroprotective and antiinflammatory ectivities of Cuphea aequipetala infusión. J. Ethnopharm, 151(2), 990998.

Pedreschi, R., \& Cisneros-Zevallos, L. (2007). Phenolic profiles of Andean purple corn (Zea mays L.). Food Chem., 100(3), 956-963.

Pereira, C. G., Carvalho, J. E., \& Meireles, M. A. (2006). Anticancer activity of Tabernaemontana catharinensis extract obtained by supercritical fluid extraction. Braz. J. Med. Biol. Res, 8(4), 144-149.

Pérez-Amador, M. C., Ocotero, V., Benitez, S., \& Jiménz, F. (2008). Vernonia patens Kunth, an Asteracea species with phototoxic and pharmacological activity. $\square$ YTHON, 77, 275-282.

Pérez-Saad, H., \& Buznego, M. T. (2008). Behavioral and antiepileptic effects of acute adminitration of the extract of the plant Cestrum nocturnum Lin (lady of the night). Epilepsy \&Behavior, 12(3), 366-372.

Poma, A., Marcozzi, G., Cesare, P., Carmignani, M., \& Sapano, L. (1999). Antiproliferative effect and apoptotic response in vitro of human melanoma cells to liposomes containing the ribosome-inactivating protein luffin. Biochim. Biophys. Acta, 1472(12), 197-205. 
Quintero, A., Pelcastre, A., \& Solano, J. D. (1999). Antitumoral activity of new pyrimidine derivates of sesquiterpene lactones. J. Pharm. Pharm. Sci., 2, 108-112.

Rajasree, R. S., Sibi, P. I., Francis, F., \& William, H. (2016). Phytochemicals of Cucurbitaceae Family - A Review. Int. J. Pharmacogn. Phytochem. Res., 8(1), 113-123.

Rodrigues, L. B., Oliveira Brito Pereira Bezerra Martins, A., Cesário, F. R. A. S., Ferreira e Castro, F., de Albuquerque, T. R., Martins Fernandes, M. N., ... Alencar de Menezes, I. R. (2016). Anti-inflammatory and antiedematogenic activity of the Ocimum basilicum essential oil and its main compound estragole: In vivo mouse models. ChemicoBiological Interactions, 257, 14-25. https://doi.org/10.1016/j.cbi. 2016.07.026

Rodríguez-Chávez, J. L., Egas, V., Linares, E., Bye, R., Hernández, T., Espinosa-García, F. J., \& G. Delgado. (2017). Mexican Arnica (Heterotheca inuloides Cass. Asteraceae: Astereae): Ethnomedical uses, chemical constituents and biological properties. Journal of Ethnopharmacology, 195, 39-63.

Saeidinia, A., Keihanian, F., Delavar, S. F., Keihanian, F., Ranjbar, A., \& M.F. Karkan. (2016). Lack of antibacterial activity of Ruta graveolens extracts against Enterococcus fecalis. PakJ Pharm Sci, 29(4), 1371-1374.

Saharkhiz, M. J., Motamedi, M., Zomorodian, K., Pakshir, K., Miri, R., \& Hemyari, K. (2012). Chemical Composition, Antifungal and Antibiofilm Activities of the Essential Oil of Mentha piperita L. ISRN Pharmaceutics, 2012, 1-6. https://doi.org/10.5402/ 2012/718645

Saldierna, J. F., Suárez, G. S., García, O. P., \& Rodríguez, S. J. (2001). Recetario de hierbas y plantas medicinales. Ediciones EuroMéxico.

Shaikh, A. M., Shrivastava, B., Apte, K. G., \& Navale, S. D. (2016). Medicinal Plants as Potential Source of Anticancer Agents: A Review. J. Pharm. Phytochem, 5(2), 291295.

Sindhu, S., \& Manorama. (2014). Ethnobotanical, Phytochemical and invitro antioxidant activity of medicinal plant Pimenta dioica (1.) Merr. (Myrtaceae) from Attappadi, Palakkad district, Kerala. Res. In Pharm, 4(1), 1-7.

Singh, S., Sharma, P. K., Kumar, N., \& Dudhe, R. (2010). Biological activities of Aloe vera. Internal. J. Pharm. Tech, 2(3), 259-280.

Suffness, M., \& Pezzuto, J. M. (1990). Assays related to cancer drug discovery. In H. K. (Ed.), Methods in Plant Biochemistry: Assays for Bioactivity (pp. 71-133). Academic Press, London.

Sukandar, E. Y., Sigit, J. I., \& Adiwibowo, L. F. (2013). Study of Kidney repair mechanisms of Corn Silk (Zea mays L. Hair)-Binahong (Anredera cordifolia (Ten) Steenis) Leaves combination in rat model of kidney failure. Inter. J. Pharm., 9(1), 12-23.

Sultana, S., Khan, A., Safhi, M., \& A. Alhazmi H. (2016). Cough suppressant Herbal Drugs: A Review. J. Pharm. SCi. Invention, 5(1), 15-28.

Tiwari, S. (2008). Plants: A rich source of Herbal medicine. J. Nat. Prod, 1, 27-35.

Toyang, N. J., Toyang, A. N., \& Toyeng, T. N. (2012). Anticancer Compounds from Vernonia guineensis.

UNAM. (2009a). Atlas de la medicina tradicional mexicana: Ala de murciélago. Retrieved April 4, 2018, from http://www.medicinatradicionalmexicana.unam.mx/ monografia.php

UNAM. (2009b). Atlas de la medicina tradicional mexicana: Asoñate. Retrieved April 4, 2018, from

http://www.medicinatradicionalmexicana.unam.mx/monografia.php?1=3\&t=\&id=7999

UNAM. (2009c). Atlas de las plantas de la medicina tradicional mexicana: Calahuala. Retrieved April 4, 2018, from http://www.medicinatradicionalmexicana.unam.mx/ monografia.php? $1=3 \& \mathrm{t}=$ \&id $=7317$

UNAM. (2009d). Atlas de las plantas de la medicina tradicional mexicana: Caña o caña morada. Retrieved from http://www.medicinatradicionalmexicana.unam.mx/ monografia.php? $1=3 \& \mathrm{t}=$ Saccharum officinarum $\& \mathrm{id}=7332$

UNAM. (2009e). Atlas de las plantas de la medicina tradicional mexicana: Chilillo. Retrieved April 4, 2018, from http://www.medicinatradicionalmexicana.unam.mx/ 
monografia.php? $=3 \& \mathrm{t}=$ \&id $=7219$

UNAM. (2009f). Atlas de las plantas de la medicina tradicional mexicana: Espinosilla. Retrieved April 4, 2018, from http://www.medicinatradicionalmexicana.unam.mx/ monografia.php? $1=3 \& \mathrm{t}=$ espinosilla\&id $=7538$

UNAM. (2009g). Atlas de las plantas de la medicina tradicional mexicana: Hierba dulce. Retrieved April 4, 2018, from http://www.medicinatradicionalmexicana.unam.mx/ monografia.php $?=3 \& \mathrm{t}=$ hierba dulce $\& i d=7979$

UNAM. (2009h). Atlas de las plantas de la medicina tradicional mexicana: Hoja Santa. Retrieved April 4, 2018, from http://www.medicinatradicionalmexicana.unam.mx/ monografia.php $?=3 \& \mathrm{t}=$ hierba santa\&id $=7699$

UNAM. (2009i). Atlas de las plantas de la medicina tradicional mexicana: Kouapajxiuit o Santa Elena. Retrieved April 4, 2018, from http://www.medicinatradicionalmexicana.unam.mx/flora2.php?l=4\&t=SantaElena\&po $=$ nahua\&id $=5041 \&$ clave_region $=22$

UNAM. (2009j). Atlas de las plantas de la medicina tradicional mexicana: Lengüa de ciervo. Retrieved April 4, 2018, from http://www.medicinatradicionalmexicana.unam.mx/ monografia.php $?=3 \& \mathrm{t}=$ Tectaria heracleifolia\&id $=7404$

UNAM. (2009k). Atlas de las plantas de la medicina tradicional mexicana: Limón. Retrieved April 4, 2018, from http://www.medicinatradicionalmexicana.unam.mx/ monografia.php $?=3 \& \mathrm{t}=$ Citrus limon $\& \mathrm{id}=7412$

UNAM. (20091). Atlas de las plantas de la medicina tradicional mexicana: Mirto. Retrieved April 4, 2018, from http://www.medicinatradicionalmexicana.unam.mx/ monografia.php? $1=3 \& \mathrm{t}=\& \mathrm{id}=7720$

UNAM. (2009m). Atlas de las plantas de la medicina tradicional mexicana: Mozote. Retrieved April 4, 2018, from http://www.medicinatradicionalmexicana.unam.mx/ monografia.php? $1=3 \& \mathrm{t}=$ \&id $=7733$

UNAM. (2009n). Atlas de las plantas de la medicina tradicional mexicana: Muicle. Retrieved April 4, 2018, from http://www.medicinatradicionalmexicana.unam.mx/ monografia.php? $=3 \& \mathrm{t}=$ muicle $\& \mathrm{id}=7981$

UNAM. (2009o). Atlas de las plantas de la medicina tradicional mexicana: Sauco. Retrieved April 4, 2018, from http://www.medicinatradicionalmexicana.unam.mx/ monografia.php $?=3 \& \mathrm{t}=$ sauco $\& \mathrm{id}=7491$

UNAM. (2009p). Atlas de las plantas de la medicina tradicional mexicana: Zacapale. Retrieved April 4, 2018, from http://www.medicinatradicionalmexicana.unam.mx/ monografia.php? $1=3 \& \mathrm{t}=$ \&id $=7419$

UNAM. (2009q). Atlas de las plantas de la medicina tradicional mexicana:c. Astzomiate. Retrieved April 4, 2018, from http://www.medicinatradicionalmexicana.unam.mx/ monografia.php?1=3\&t=Plumeria acutifolia\&id $=7302$

UNAM. (2009r). Atlas de las plantas de la medicina tradicional mexicana:e. Caña de venado. Retrieved April 4, 2018, from http://www.medicinatradicionalmexicana.unam.mx/ monografia.php? $=3 \& \mathrm{t}=$ Costus pulverulentus $\& \mathrm{id}=7038$

Uriostegui, M. T. (2014). Análisis fitoquímico y efecto antiproliferativo de genotipos de Sechium edule (Jacq.) Sw. Sobre cáncer de mama. Colegio de Postgraduados.

Via, L. D., Mejía, M., García-Argáez, A. N., Braga, A., Toninello, A., \& Martínez-Vázquez, M. (2015). Anti-inflammatory and antiproliferative evaluation of 4b-cinnamoyloxy, $1 \mathrm{~b}$, 3a-dihydroxyeudesm-7, 8-ene from Verbesina persicifolia and derivatives. Bioorg. Med. Chem., 23(17), 5816-5828.

Vidal, F., Vidal, J. C., Gadelha, A. P. R., Lopes, C. S., Coelho, M. G. P., \& Monteiro-Leal, L. H. (2007). Giardia lamblia: The effects of extracts and fractions from Mentha piperita Lin. (Lamiaceae) on trophozoites. Exp. Parasitology, 115(1), 25-31.

Vijitha, T. P., \& Saranya, D. (2017). Corn Silk-A medicinal boon. Intern. J. Chem. Tech. Research, 10(10), 129-137.

Villavicencio, N. M. A., \& Pérez, E. B. E. (2006). Pantas útiles del Estado de Hidalgo III. Universidad Autónoma del Estado de Hidalgo, México. 
Recibido:

7/octubre/2017

Aceptado:

6/diciembre/2018
Waizel-Bucay, J. (2002). Uso tradicional e investigación científica de Talauma mexicana. Rev. Mex. Cardiol., 13(1), 31-38.

Waizel-Bucay, J., Martínez-Porcayo, G., Villarreal-Ortega, M. L., Alonso.Cortés, D., \& A. Pliego-Castañeda. (2003). Estudio preliminar etnobotánico, fitoquímico, de la actividad citotóxica y antimicrobiana de Cuphea aequipetala Cav. (Lythraceae). Polibotánica, 15, 99-108.

Wang, J., Li, J., Zhao, P., Ma, W., Feng, X., \& Chen, K. (2015). Antitumor Activities of Ethyl Acetate Extracts from Selaginella doederleinii Hieron In Vitro and In Vivo and Its Possible Mechanism. Evidence-Based Complementary and Alternative Medicine, 2015, 1-9. https://doi.org/10.1155/2015/865714

Whelan, L. C., \& Ryan, M. F. (2003). Ethanolic extracts of Euphorbia and other ethnobotanical species as inhibitors of human tumor cell growth. Phytomedicine, 10, $53-58$.

Wong, F. C., Woo, C. C., Hsu, A., \& Tan, B. K. H. (2013). The Anti-Cancer Activities of Vernonia amygdalina Extract in Human Breast Cancer Cell Lines Are Mediated through Caspase-Dependent and p53-Independent Pathways. PLoS ONE, 8(10), e78021. https://doi.org/10.1371/journal.pone.0078021

Wu, T. H., Chow, L. P., \& Lin, J. Y. (1998). Sechiumin, a ribosome-inactivating protein from the edible gourd, Sechium edule Swartz-purification, characterization, molecular cloning and expression. Eur. J. Biochem., 255, 400-408.

Zavala-Sánchez, M., Pérez-Gutiérrez, S., Pérez-González, C., Sánchez-Saldivar, D., \& L. AriasGarcía. (2002). Antidiarrohoeal activity of Nonanal, an Aldehyde isolated from Artemisia ludoviciana. Pharm Biol., 40(4), 263-268. 